IZA DP No. 7273

The Importance of the Cognitive Environment for Intertemporal Choice

Michael A. Kuhn

Peter Kuhn

Marie Claire Villeval

March 2013 


\title{
The Importance of the Cognitive Environment for Intertemporal Choice
}

\author{
Michael A. Kuhn \\ uC San Diego \\ Peter Kuhn \\ UC Santa Barbara, \\ NBER and IZA \\ Marie Claire Villeval \\ University of Lyon, CNRS, GATE \\ and IZA
}

Discussion Paper No. 7273

March 2013

\author{
IZA \\ P.O. Box 7240 \\ 53072 Bonn \\ Germany \\ Phone: +49-228-3894-0 \\ Fax: +49-228-3894-180 \\ E-mail: iza@iza.org
}

Any opinions expressed here are those of the author(s) and not those of IZA. Research published in this series may include views on policy, but the institute itself takes no institutional policy positions. The IZA research network is committed to the IZA Guiding Principles of Research Integrity.

The Institute for the Study of Labor (IZA) in Bonn is a local and virtual international research center and a place of communication between science, politics and business. IZA is an independent nonprofit organization supported by Deutsche Post Foundation. The center is associated with the University of Bonn and offers a stimulating research environment through its international network, workshops and conferences, data service, project support, research visits and doctoral program. IZA engages in (i) original and internationally competitive research in all fields of labor economics, (ii) development of policy concepts, and (iii) dissemination of research results and concepts to the interested public.

IZA Discussion Papers often represent preliminary work and are circulated to encourage discussion. Citation of such a paper should account for its provisional character. A revised version may be available directly from the author. 


\section{ABSTRACT \\ The Importance of the Cognitive Environment for Intertemporal Choice*}

We experimentally manipulate two aspects of the cognitive environment, cognitive depletion and recent sugar intake, and estimate their effects on individuals' time preferences in a way that allows us to identify the structural parameters of a simple $(\alpha, \beta, \delta)$ intertemporal utility function for each person. We find that individuals exposed to a prior cognitive load, individuals who consumed a sugared drink, and individuals who consumed a sugar-free drink all defer more income than a control group exposed to none of these conditions. Structural estimates show that all three effects are driven entirely by increases in the intertemporal price elasticity parameter $(\alpha)$. Together, our results suggest that at least for complex economic decisions like intertemporal financial choice, the 'attention/focusing' effect of both prior cognitively demanding activity and prior assignment of a primary reward can improve decision-making.

JEL Classification: C91, D90

Keywords: $\quad$ time preferences, self-control, depletion, sucrose, experiment

Corresponding author:

Marie Claire Villeval

GATE (Groupe d'Analyse et de Théorie Economique)

CNRS - University of Lyon

93 Chemin des Mouilles

F-69130 Ecully

France

E-mail: villeval@gate.cnrs.fr

\footnotetext{
* This research has been supported by a grant from the French National Research Agency (ANR, EMCO program, HEIDI grant) and was performed within the framework of the LABEX CORTEX (ANR11-LABX-0042) of Université de Lyon, within the program "Investissements d'Avenir" (ANR-11-IDEX007) operated by the French National Research Agency (ANR). We thank James Andreoni and Charles Sprenger for valuable feedback.
} 


\section{Introduction}

Formal economic models rarely consider the effects of the cognitive environment when making predictions about human behavior, but people do all the time: it seems common sense not to ask friends, family or colleagues to perform important tasks when they're tired or hungry, and to avoid making important decisions ourselves under those conditions. This intuition has been confirmed by a number of recent studies by psychologists, which show that temporary conditions such as prior performance of a cognitively demanding task or a low level of blood glucose can alter decisions, especially decisions involving the exercise of willpower. While this result has been replicated for a number of tasks in a laboratory environment (see Gaillot and Baumeister 2007 for a recent review), an intriguing recent field example comes from Danziger, Levav and Avanaim-Pesso (2011). Looking at more than 1100 decisions made by an Israeli parole board, they determined that parole was much more likely to be granted early in the day than later in the day (i.e., after having heard a number of cases), conditional on a number of important factors including crime, sentence and ethnicity. Since a judge's reputation is harmed more by inappropriately granting than refusing parole, there is a sense in which fatigued judges 'take the easy way out' relative to rested judges. A fascinating footnote to the story is that following the parole board's midmorning snack, there was a substantial spike in the percentage of prisoners who were granted parole.

These findings seem intuitive when considering how to prepare for a difficult exam, a public performance or a situation requiring emotional restraint. But the relevance of the cognitive environment for many important economic decisions remains unclear. Factors that affect immediate actions like using racial stereotypes or inflicting pain on others may not affect economic decisions -such as how much financial risk to accept or how to allocate income over time- at all, or in the same way. For this reason, this paper studies the effects of temporary manipulations in the cognitive environment on time preferences over income. We ask whether performing a task that can be considered cognitively depleting affects subsequent intertemporal choices. If so, is the effect consistent with our intuition that cognitive depletion should make choices (subjectively) "worse"? Similarly, does administering a sugar supplement affect intertemporal choice? If so, does this effect work counter to that of cognitive depletion such that it could be used as a remedy, helping people to better concentrate their energy on the task? Specifically, adapting the Convex Time Bud- 
get technique developed by Andreoni and Sprenger (2012a) we allow participants in a laboratory experiment to make a series of choices about payments that they will receive sooner or later, facing positive interest rates. At interest rates well above those available outside the lab, we measure subjects' propensities to get their money sooner rather than later, and study how this varies across treatments related to cognitive depletion and sugar consumption. Because our procedure allows us to recover the structural parameters of a widely used intertemporal utility function, specifically the discount rate, present bias and intertemporal elasticity of substitution, for each subject in our sample, it allows us to translate the abstract concept of willpower into quantitative statements that are relevant to decisions like mortgage refinancing, retirement planning, payday advances and human capital investments.

We find that time preferences are sensitive to transient features of the cognitive environment, but we do not find that cognitive depletion makes subjects more impulsive. Instead, participants who have been exposed to a cognitively depleting task (the Stroop, 1935, test in which better performance requires resisting the temptation of giving automatic answers) exhibit increased patience in the subsequent time preference elicitation. ${ }^{1}$ We also find that fasted participants given a sugared beverage prior to the time preference elicitation are more patient, but that a placebo beverage produces a similar, albeit less powerful, effect. These effects are economically significant in magnitude, corresponding to large differences in demand for short-term loans. While our results apply to a sample pool with above-average cognitive skills relative to the population (undergraduate students at selective universities), all the above effects are absent in a subsample with very high measures of cognitive ability. ${ }^{2}$

Insights into the possible causal mechanisms behind these effects come, in part, from our structural estimates of preference parameters. Both our descriptive estimates of price-sensitivity and our structural estimates indicate that the clear majority of the effect of all of our treatments (whether depletion, sugar drink or placebo drink) is not on the subjective discount rate or present bias parameters, but on the intertemporal elasticity of substitution. Essentially, while subjects in all treatments

\footnotetext{
${ }^{1}$ Throughout this paper we use 'patience' as convenient shorthand for a tendency to delay the receipt of income, holding other conditions (prices, amount of delay), constant. Since 'patience' is sometimes also used, more specifically, to refer to an absence of present bias in a structural model of choice, we will be explicit whenever we discuss present bias per se.

${ }^{2}$ We determine membership in this subsample using the French post-secondary school examination. This is commonly thought of as a measure of cognitive ability or intelligence, but we make no assertion as to what exactly it measures: effort, attention, recall, reasoning, logic or some other characteristic.
} 
choose the same level of early income when early income is cheap, treated subjects are much more likely to reduce their early payment when its relative price rises. This suggests a model in which at least for complex decisions like intertemporal financial choice, the 'attention/focusing' effect of prior cognitively demanding activity can outweigh the effects of depletion and spillover on the subsequent time preference elicitation task. Our results also suggest that giving our subjects a prior primary reward (the drink) may help them to better concentrate on the conditions of the intertemporal choice, and cast some doubt on the role of blood glucose per se in mediating intertemporal economic choices.

This finding has an interpretation consistent with the Chabris, Laibson and Schuldt's (2008) arbitrage critique of intertemporal choice experiments conducted using cash payments. When subjects are actively aware of their outside options, their choices should only reveal their available borrowing or saving rates. Interventions that help make individuals more aware and active in their choices should push observed preferences towards linearity, such that when laboratory prices increase past a certain point, subjects should make big allocation changes from one corner solution to the other.

Policymakers, especially those who deal with consumer finances and financial literacy, should be concerned if preferences are highly sensitive to small changes in the environment. Recent papers from Benartzi and Thaler (2001), Thaler and Benartzi (2004), as well as Beshears et al. (2011, 2013), Carroll et al. (2009) and Choi, Laibson and Madrian (2009), establish serious pitfalls in financial literacy amongst typical American investors. The proportion of stocks in a portfolio depends on the proportion of stocks offered amongst plan options, and even dramatically simplified mutual fund disclosures do not help people avoid sales loads. They also demonstrate that forcing active rather than passive choice and manipulating the default option are effective tools for improving decision making. Our results suggest that attention-focusing tasks and remedying energy deficits may help stimulate the same type of active choice, and that these effects are important even for college-educated subjects (though not for the most cognitively able of that group).

The remainder of this paper is organized as follows. Section 2 presents a review of the relevant literature in psychology and economics. Section 3 details the experimental design. We present our data analysis in Section 4 while Section 5 discusses our results and concludes. 


\section{Related Literature}

Experiments on willpower are common in psychology. The Stanford marshmallow experiment, conducted by Mischel, Ebbesen and Raskoff Zeiss (1972) is a well-known example. They determined that older children were better able to resist the temptation to eat a marshmallow for fifteen minutes in order to double their reward, but that overall, only about a third of the 90 participants were able to do so. A followup study by Shoda et al. (1990) demonstrated that the ability to delay gratification in the original experiments was correlated positively with SAT scores. ${ }^{3}$ Another by Casey et al. (2011) showed that there were detectable brain activity differences during willpower tasks exhibited between the adults who could and could not resist the marshmallow as children, 40 years earlier. In economics, Dohmen et al. (2010) found that individuals with higher cognitive ability are more patient over a yearlong horizon. Taken together, these studies suggest that a person's capacity to exert willpower appears to be a relatively permanent characteristic that varies substantially across individuals, and is correlated with cognitive ability.

More recently, and more relevant to our study, psychologists have also documented links between the cognitive environment at the time a decision is made, specifically whether the individual concurrently or very recently engaged in a task that required cognitive exertion, and numerous behaviors that require self-control or patience. The prior exertion of effort in these studies is a transient characteristic that can substantially alter behavior in a task with completely unrelated incentives. Muraven and Baumeister (2000) have shown that exerting self-control consumes limited resources and, as a consequence, subsequent attempts to control the self are less likely to succeed. DeWall et al. (2007) found that participants in a lab study who were forced to restrain themselves from eating a donut for five minutes acted more aggressively in a subsequent task. DeWall et al. (2008) deplete participants by having them establish a habit and then break it; they find that these subjects are less likely to donate food or money in a hypothetical scenario than those who did not have to break the habit. Also, participants who were asked to pay close attention to a video are less likely to volunteer aid to victims of a recent tragedy than those who watched the video normally. Mead et al. (2009) also find that cognitive depletion increases dishonesty for personal gain. Baumeister et al. (2006) suggest that the desires to act spitefully or dishonestly are natural traits

\footnotetext{
${ }^{3}$ Funder and Block (1989) establish a similar relationship with IQ, and Kirby, Winston and Santiesteban (2005) do so with college GPA.
} 
that individuals have to exert willpower to control. Cognitive depletion would act as a mediator of the expression of these desires via the stock of available willpower.

While economists have long argued that interpersonal differences in subjective discount rates and cognitive ability might account for a significant share of economic inequality, and that present bias could explain temporally inconsistent behavior, they have devoted little attention to the effects of the immediate cognitive environment on intertemporal choices. ${ }^{4}$ Bucciol, Houser and Piovesan (2011a) demonstrate that productivity of younger children in a simple craft task is negatively affected by prior exposure to consumption temptation while that of older children is not. This could suggest a mediating role for cognitive ability in willpower interventions (see Bucciol, Houser and Piovesan 2011b, for a survey on willpower in adults and children). Houser, Reiley and Urbancic (2008) have found that the amount of time individuals spend waiting in line at a grocery store is positively related to the probability that they add a tempting item to their overall purchase. This finding is consistent with the idea that willpower can be depleted over time. Additionally, Burger, Charness and Lynham (2011) reveal a significant impact of depletion via the Stroop (1935) task on procrastination; but as in this work, they also find that depletion actually improves task performance in the longer run. ${ }^{5}$ Benjamin, Brown and Shapiro (2013) find that distracting participants during their work increases small-stakes risk aversion, while asking them to provide the reasoning for their decisions decreases small-stakes risk aversion.

Finally, Ifcher and Zarghamee (2011) find that inducing mild positive affect using a video clip leads to more patient decisions involving income receipt over time. ${ }^{6}$ In addition to focusing on two aspects of the cognitive environment (depletion and sugar intake) that have recently attracted considerable attention among psychologists, a key difference between our study and Ifcher and Zarghamee's (2011) is our focus on precisely how our treatments affect time preference - do they act on the discount factor, the level of present bias, or on subjects' sensitivity to intertem-

\footnotetext{
${ }^{4}$ See Ryder (1985) for an early theoretical treatment of the long-term effects of discount rate heterogeneity, and Anderson et al. (2011) for evidence on the long-term effects of heterogeneity in both discount rates and cognitive ability. Laibson (1997) and O'Donoghue and Rabin (1999) study the effects of present bias.

${ }^{5}$ There is theoretical work on this exact issue as well: Ozdenoren, Salant and Silverman (2012) construct a model in which depletion helps explain time preference reversals and procrastination; exerting self-control depletes willpower in the short run but increases it in the long-run, like a muscle.

${ }^{6}$ Neuroscience studies that look at the sensitivity of intertemporal choice to emotional primes have shown both higher activation of the posterior sector of the anterior cingulate cortex resulting from a fear prime and increases in farsightedness due to an inhibition spillover effect (Luo, Ainslie and Monterosso 2010).
} 
poral prices? - and on how all these effects are mediated by cognitive ability. Distinguishing these effects sheds light on alternative mechanisms via which the cognitive environment affects intertemporal choice that cannot be inferred from an experimental design and estimation framework that interprets treatment effects as acting on subjects' discount factor only. Our finding that the treatments act on the intertemporal substitution elasticity suggests that they induce more focus and attention on the choice task, leading lower-test-score subjects to substitute away from high-priced options in situations where they otherwise would not.

Given the small amount of economic research on the effects of cognitive depletion on decisions, it is not surprising that essentially all the literature on physiological interventions that might remedy depletion (such as sugar consumption) has been done by psychologists and neuroscientists. ${ }^{7}$ Among these studies, Gailliot and Baumeister (2007) show that exerting self-control uses a large amount of blood glucose which is the primary energy source for the body's cells and that failures of self-control are more likely when blood glucose is low. In addition, Gailliot et al. (2007) show that self-control may depend on glucose as a source of energy: consuming a drink containing sucrose (which is rapidly metabolized into glucose) eliminates the impairments of performance in a self-control task due to participation in an initial act of self-control. Mead et al. (2009) also find that the consumption of a sugared beverage helps mitigate the effects of depletion on self-control and willpower. Gailliot et al. (2009) find that these drinks decrease the use of stereotypes and slurs. These studies are built around the Energy Model of self-control; energy is a stock required to exert self-control that can be affected by cognitive exertion and glucose interventions. ${ }^{8}$

There is, however, conflicting physiological evidence on the mechanism by which glucose may affect willpower. In response to the works cited above, Molden et al. (2012) use precise measures of blood glucose levels to demonstrate that exerting willpower does not decrease this stock, and that neither levels nor changes in blood glucose bolster effort on a subsequent task. They additionally show that simply rinsing one's mouth with a sugar beverage without swallowing

\footnotetext{
${ }^{7} \mathrm{~A}$ loosely related branch of literature in labor economics studies of the effects of breakfast and nutrition programs in schools on educational outcomes. Wesnes et al. (2003) finds that breakfast interventions do increase attention and memory. Notably, a glucose drink alone increased the speed at which items could be retrieved from memory for 90 minutes following consumption. Dotter (2013) uses a natural experiment to show that universally-free breakfast programs have large positive effects on both math and reading scores.

${ }^{8}$ The glucose level fluctuates with the cognitive processes relying on executive functions. In particular, a low level of glucose correlates with a low performance in the difficult trials of the Stroop test, but not in the easy trials (see Benton, Owens and Parker 1994, and Gaillot et al. 2007).
} 
(with no effect on blood glucose) bolsters self-control. ${ }^{9}$ Neurological evidence indicates that the sensing of the carbohydrate in the mouth activates a part of the brain that is highly sensitive to incentives (Kringelbach 2004; Chambers, Bridge and Jones 2009). The presence of actual sugar as opposed to an artificial sweetener is critical in generating this response. This pathway is referred to as the Motivational Model of self-control. Importantly, our method of sugar delivery should reinforce self-control according to both the Motivational and the Energy models.

Relative to the above literatures, this paper is the first to study the effects of two key aspects of the cognitive environment - cognitive depletion and sugar consumption - on an economic choice that sits at the heart of many of the discipline's models: the intertemporal allocation of monetary income. Further, we formalize the rather fluid concept of willpower by specifying an intertemporal utility function with three parameters, each of which corresponds to a conceptually distinct aspect of "impatience" or "impulsivity", and empirically estimate treatment effects on all three parameters. Additionally and again uniquely, we study how a semi-permanent individual characteristic, cognitive ability, mediates the effects of temporary manipulations of the cognitive environment: are smarter people's intertemporal allocation decisions less affected by being hungry or by engaging in a depleting activity?

Aside from estimating the effects of cognitive and physiological interventions, this paper also contributes to the recent economic literature on the measurement of time preferences. Our methodology, the Convex Time Budget (CTB henceforth), was developed by Andreoni and Sprenger (2012a) in response to concerns that using information on risky choices to estimate the curvature of utility functions over certain outcomes could bias the measured intertemporal preferences. We modify the CTB technique by calibrating our prices to detect more subtle differences in preferences. Our results showcase 'realistic' (relative to typical rates for payday loans) and precise discount rate estimates. This paper replicates previous successful implementations of this technique.

A final related literature, albeit very small, is an economic literature that designs experiments with the aim of estimating the parameters of a structural model of preferences as outcome variables. Numerous well-known lab and field experiments use treatment variation to identify structural parameters (DellaVigna, List and Malmendier 2012; Charness and Rabin 2002), but very few

\footnotetext{
${ }^{9}$ See also Sanders et al. (2012).
} 
estimate structural parameters separately for treatment and control groups so as to test the difference. Callen et al. (2013) examine whether exposure to traumatic violence and the priming thereof combine to affect expressed risk preferences and Carvalho, Prina and Sydnor (2013) randomly allocate savings accounts to low-income households and estimate the effect of this intervention on time preferences months later. Papers in this category, including ours, also speak to the broader literature on the (in)stability of preferences.

\section{The Experiment}

\subsection{Treatments}

Our experiment consists of three types of sessions: Baseline, Depletion and Drink. Within each session type, there are five distinct parts, the orders of which change across session type. In a Drink session, the phases are: (1) consumption of drink and entry questions, (2) rest to allow any sucrose in the drink to be metabolized into blood glucose, (3) elicitation of time preferences, (4) depletion of self-control in the Stroop test, and (5) an exit survey that includes Frederick's (2005) Cognitive Reflection Test (CRT). The structure of the Baseline sessions is similar to that of Drink sessions, except that no beverage is given. In Depletion sessions, we invert the order between the Stroop test and the elicitation of time preferences. Finally, within the Drink sessions, we have two conditions corresponding to a drink containing sugar or a sugar-substitute. These variations give us four treatments: Baseline, Depletion, Placebo and Sugar. Table 1 lays out the progression of the experiment for each treatment.

\section{Table 1 about here}

The comparison between the Depletion treatment and the Baseline allows us to determine whether performing an initial task that requires impulse control affects the decision to defer income in the time preference task. The comparison between the Sugar treatment and the Placebo treatment allows us to study whether the consumption of sugar affects time preferences. Finally, if time preferences react to the consumption and metabolization of sucrose rather than the drink itself, we expect to observe no differences in choices when comparing the Placebo treatment and the Baseline. We discuss each task and drink consumption in more detail below. 


\subsection{Time Preference Elicitation}

To elicit time preferences, we implement the Convex Time Budget (CTB) method of Andreoni and Sprenger (2012a, henceforth AS) instead of the more common approach of using multiple-price lists (Harrison, Lau and Williams 2002). ${ }^{10}$ Among other advantages, this approach measures both discount rates and the concavity of utility while the multiple price list method usually assumes linear utility. ${ }^{11}$ In addition, it may be a preferable approach for estimating individual-specific preference parameters because the convex choice set means that each choice an individual makes carries more information than if the choice were from a binary set. ${ }^{12}$

In every choice, participants received a budget of 16 tokens to allocate between an early payment, $c_{t}$, and a late payment, $c_{t+k}$, with $t$ the early payment date and $k$ the delay between the two dates. Participants made 45 allocation decisions and one of these decisions was randomly selected at the end of the session for actual payment according to the allocation of tokens between the two dates. The 45 budgets combine three early payment dates $(t=0,5,15$ weeks), three delay lengths ( $k=5,10,15$ weeks) and various price ratios. Thus, there were only seven paydays evenly spaced at five weeks intervals $(0,5,10,15,20,25,30$ weeks $)$. For each $(t, k)$ combination, participants had to make five decisions involving various interest rates. We defined three rate progressions that were combined with the various early payment dates while the combination of budget progressions and delay lengths were kept constant. The value of a token at the late date, $a_{t+k}$, was always equal to $€ 1$, while the value of the token at the early date, $a_{t}$, varied between a minimum of $€ 0.67$ and a maximum of $€ 0.99$. Allocating all the tokens to the late payment date paid $€ 16$; allocating all the tokens to the early payment date paid a minimum of $€ 10.72$ and a maximum of $€ 15.84$. The progressions were defined in order to offer implied annual interest rates, compounded quarterly, between $4 \%$ and $845 \%$. Table A1 in the Appendix presents all the choice sets.

The presentation of the 45 decisions was very similar to that in AS. A choice screen had nine

\footnotetext{
${ }^{10}$ With multiple price lists, the participants have to choose several times between a smaller early payment and a larger later payment with a monotonically increasing interest rate. Individual time preferences are captured by the point where the individual switches from the early payment to the later payment.

${ }^{11}$ Andersen et al. (2008) augment a time multiple-price list with a risk multiple price list to avoid this assumption, but this fix relies heavily on the expected-utility assumption of continuity in probability for its validity. Andreoni and Sprenger (2012b) demonstrate, exactly in the context of intertemporal choice, the failure of this assumption.

${ }^{12}$ Every choice from a convex set identifies the exact point at which the optimality condition of the decision problem holds. Choices from binary sets generate inequalities that bound parameter values. Repetition of the task produces overlapping intervals that shrink the bounds and asymptotically generate parameter estimates. With finite date, probabilistic choice approaches are necessary to identify parameters.
} 
decision tabs that were displayed successively and corresponded to the nine $(t, k)$ combinations. The order between the nine tabs was randomly and independently determined for each participant to control for order effects. Each decision tab displayed five budget decisions presented in order of increasing gross interest rate. To facilitate decision-making by a better visualization of delays, each decision tab displayed a dynamic calendar highlighting the current date, the early date and the late date in different colors. It also displayed the values of a token at the early date and at the late date, together with the values in Euros of the earnings corresponding to the decisions. A sample decision tab is reproduced in the Appendix. The boxes for entering the allocation decisions were initially blank. As soon as a value was entered either for the early date or the late date, the other box was filled automatically to ensure that the total budget was 16 tokens and the corresponding payoffs in Euro at the two dates were also displayed.

This design allows us to estimate for each individual her discount rate, the curvature of her utility function (through the variations of $k$ and of the gross interest rate), and her present bias and hyperbolic discounting (through the variation of $t$ ). In addition, it allows us to examine which, if any, of these dimensions is impacted by self-control depletion and sucrose consumption.

\subsection{Cognitive Depletion}

We used a Stroop test (Stroop, 1935) to deplete self-control as shown by studies in social psychology (for a survey of the test, see MacLeod 1991). In a typical Stroop test, individuals have to read the color of ink used to write words independently of the color names of words. In some trials, there is congruence between the color of the word and the color of the ink (the word "yellow" is written in yellow) but in other trials there is no congruence (the word "yellow" is written in red and the correct answer is red). The incongruent stimuli typically require more time and produce more mistakes than the congruent stimuli because the brain automatically decodes the semantic meaning of the word and needs to override its first reaction to identify the color of the ink. Shortcutting the automatic process requires self-control.

In our experiment, the participants' computer screen displayed a series of color words (black, blue, yellow, green and red) successively, and the participants were instructed to indicate, as quickly and accurately as possible, the ink color in which the word was written. The list of pos- 
sible colors was displayed at the bottom of the screen and the participants had to press the button corresponding to the color of the ink, whether or not that matched the color name of the word (see instructions in Appendix). They had to complete congruent and incongruent Stroop trials in random order for 6 minutes. On average they completed 126 trials (S.D. = 11.69). As expected, the time spent on incongruent words was significantly higher than on the congruent words (two-tailed t-test, $p<0.001)$.

\subsection{Drink Consumption}

Following Gaillot et al. (2007), participants in each Drink session were given 14 ounces (40 centiliters) of a soft drink sweetened either with sugar or with a sugar substitute. Both types of drinks had the same appearance. The sugared drink contained 158 kilocalories and the placebo drink contained $10 .{ }^{13}$ We used a double blind procedure to administer the drinks: neither the participants nor the experimenters were aware of the sugar content of the beverage.

After being invited to drink the beverage, participants could rest in silence and read magazines that we distributed during 10 minutes in order to allow the sucrose to be metabolized into glucose. Three minutes before the end of this period, participants had to assess the beverage and to report their usual consumption of soft drinks. ${ }^{14}$ In the Baseline and the Depletion treatment, the same rest period of 10 minutes was implemented.

\subsection{Procedures}

The experiment was computerized, using the REGATE-NG software. It consisted of 8 sessions conducted at the laboratory of the GATE (Groupe d'Analyse et de Théorie Economique) institute in Lyon, France. Undergraduate students from the local engineering and business schools were

\footnotetext{
${ }^{13}$ Specifically, the drinks were Fanta "Citron frappé" and Fanta Zero "Citron frappé". They were dispensed in glasses (not the original container) and appear identical (see Figure A1 in the Appendix). Neither contains caffeine, though both contain ascorbic acid (vitamin C).

${ }^{14}$ The questions were: 1) Please rate your enjoyment of the beverage you just consumed, between 1 and 10. 2) How many calories do you think the beverage contained? 3) How often do you drink soft drinks (Coke, Pepsi, lemonade, ...): every day / every week / once or twice a month or less / less than twice a month? Although participants in the Placebo condition assessed the beverage less positively (mean $=4.55$, S.D. $=2.77$ ) than those in the Sugar condition $($ mean $=5.57$, S.D. $=2.58)($ two-tailed Mann-Whitney test, $p=0.097)$, they did not realize that they received a placebo. Indeed, they predicted the same number of calories contained in the beverage (mean $=124.16$, S.D. $=86.26)$ than the participants placed in the Sugar condition $($ mean $=140.41$, S.D. $=98.26)(p=0.497)$.
} 
invited via the ORSEE software (Greiner 2004). Between 17 and 20 participants took part in each session, for a total of 149 participants. Two sessions of the Baseline treatment were implemented with a total of 34 participants; two sessions of the Depletion treatment were implemented involving 40 participants; and four Drink sessions were implemented with 75 participants (37 in the sugar condition and 38 in the placebo condition).

The invitation message addressed to the participants of all treatments indicated that they may possibly have to drink a beverage containing sugar during the session and that individuals suffering or thinking that they may suffer from a pathology linked to blood glucose regulation (like diabetes) should abstain from participating. After signing up, all the participants in all the treatments were instructed not to drink or eat at least three hours prior to the beginning of the session in order to stabilize blood glucose levels. Upon arrival we recorded the time of their last intake. Since chronobiology may influence economic decision-making (see Dickinson and McElroy, 2010), all the sessions were run at noon, when the level of blood glucose is low. ${ }^{15}$

Upon arrival, the participants had to sign a consent form reminding them that they should not participate if they suffer from a disease related to failure of blood sugar regulation. Then participants randomly drew a tag from a bag assigning them to a terminal. The instructions for each segment were distributed and read aloud by the experimenter after the completion of the prior segment (see Appendix).

The elicitation of time preferences requires very strict procedural rules. To participate in the experiment, the students were required to own a personal bank account and were informed by the invitation message that they would be paid by a wire transfer to their bank account; they were required to bring us a bank statement. ${ }^{16}$ During the session, instructions informed the participants that a show-up fee of $€ 5$ (\$6.5) would be wired to their bank account in addition to their other payoffs at two different dates, regardless of their decisions: half of the show-up fee amount would be paid at the early date and the other half at the late date indicated by the decision randomly selected at the end of the session for payment. The show-up fee had no differential influence on the

\footnotetext{
${ }^{15}$ We did not measure individuals' baseline blood glucose level, which would have required taking blood samples.

${ }^{16}$ We cannot rule out that the information given in the message (payment wired to the bank account and possibility of having to drink a beverage) has led to a self-selection of participants. However, the sessions were booked as quickly as usual. In addition, we asked 44 students participating in another experiment with standard cash payment whether they owned a personal bank account; all of them answered positively. Moreover, there is no reason to believe that the two criteria for participating were correlated. Finally, the message did not mention that the payment could be made at two different dates which could have generated some self-selection.
} 
45 allocation decisions. Participants were also informed that the dates mentioned on the decision screens were the dates at which the wire transfers would be ordered by the finance department. ${ }^{17}$ To maximize the confidence of the participants about the payment of their earnings, they received a document stating that the bank transfer would be ordered by the National Center for Scientific Research (CNRS). ${ }^{18}$ In addition, the document mentioned the name, email address and phone number of the professor in charge of the experiment who could be contacted in case of any problem with the payment.

At the end of each session, participants received a feedback on the decision randomly selected for payment, indicating their payoffs and the dates of the two wire transfers for this decision. Then, they had to complete an exit survey which included questions about their demographics and average mark on the final high school exam (Baccalauréat). Sessions lasted 60 minutes and participants averaged earnings of $€ 20.43$ (\$26.62, with a standard deviation of $€ 0.97$ (\$1.26), including the show up fee.

\section{Results}

We present our results in four sections. The first section establishes a number of basic patterns in a pooled sample of all treatments, to provide context for the study of treatment effects. The second and third sections are nonparametric and structural approaches to analyzing the treatment effects, respectively. The final section presents some robustness checks. Since one of our central questions is how subjects' responses to the cognitive environment are mediated by their cognitive ability, and since a large share of our subjects has very high cognitive skills relative to the French population, we present most of our experimental results separately according to our subjects' reported achievement on the French Baccalauréat exam. ${ }^{19}$ To maximize statistical power, we simply divide our participants in half relative to the median score in our sample, which was 16. Importantly, be-

\footnotetext{
${ }^{17}$ The administration committed to respect exactly the dates of the transfers and sent us a feedback after each payment. We believe the transaction costs associated with this payment methodology are lower than the typical approach used in this type of experiment, which relies on personal checks or vouchers.

${ }^{18}$ In France, CNRS is a well-known science and technology public agency. It employs 25,000 people and it operates through 1,235 research institutes. Students are aware that the GATE institute is operated by both the CNRS and the University of Lyon.

${ }^{19}$ The French Baccalauréat exam (le bac) is taken at the end of high school (lycée). In 2012, slightly over three quarters of French youth had passed the Baccalauréat.
} 
cause only $9 \%$ of French Baccalaurat recipients earned a score of 16 or higher (our participants are drawn from selective universities), we refer to our two groups as "high score" and "lower score" respectively. Our high-scoring subjects clearly represent an elite level (about the top decile) of achievement among French high school graduates, while our lower-scoring group roughly represents the 50th through 90th percentiles. Thus the results for our lower-scoring group are more representative of a typical high school graduate in France, and we focus much of our discussion on that group. ${ }^{20}$

\subsection{Overall Features of Behavior}

We start by presenting two foundational results that verify aspects of our model and design, plus some simple descriptive statistics for the pooled sample across all treatments. The first result is that subjects' aggregate demand curves in the experiment satisfy two general predictions of utilitymaximizing intertemporal behavior.

Result 1 - Consistent with predictions for agents who discount the future and have some preference curvature, mean demand for early income exceeds half the 16-token endowment at interest rates near zero, then declines monotonically with the price of early income. This behavior characterizes both high- and lower-score participants.

A simple but general model of choice between early and late tokens for any combination of early payment date $(\mathrm{t})$ and delay $(\mathrm{k})$ supposes that subjects solve

$$
\max _{X, Y} U(X)+\lambda U(Y), \quad \text { subject to } \quad R X+Y \leq M
$$

where $X$ is experimental income received in the early period, $Y$ is experimental income received in the later period, $U^{\prime}>0, U^{\prime \prime}<0, R$ is the price of sooner income, and $M$ is the endowment. In (1), $\lambda<1$ can depend on both $t$ and $k$ to incorporate both discounting and present bias, but is fixed within any $(t, k)$ cell. $R$, on the other hand, varies within a $(t, k)$ cell as we experimentally

\footnotetext{
${ }^{20}$ The results of the Cognitive Reflection Test (CRT) performed at the end of the sessions are highly correlated with Baccalauréat score, and we can replicate all our main results using this measure of cognitive ability as well. However since subjects' CRT results could be affected by our treatments, we focus on the Baccalauréat-score based results.
} 
manipulate the implied interest rate. For this model of preferences, Figure 1 illustrates (a) that subjects should consume more than half their endowment in the early period $(X>8)$ when $R=1$ because $\lambda<1$, and that $X$ should fall monotonically as $R$ rises because income and substitution effects reinforce each other when the endowment is all in the later period, as is the case in our experiment. $^{21}$

Figure 1 about here

Both these predictions are confirmed by the evidence in Figure 2, which plots the demand curves for the early payment $(X)$, separately by score and pooled across all treatments. With the exception of the shortest delay length and latest start date for both groups, the demand curves all start at above eight units of $X$ at levels of $R$ closest to one, then fall monotonically as $R$ rises. ${ }^{22}$ The success of these basic predictions suggests that our participants' choices are informative for the preferences we wish to study.

Figure 2 about here

Result 2 - There is evidence of small but significant present bias in our data, among both highand lower-test score participants.

Participants receive the first of their two payments either on the day of the experiment, 5 weeks after the experiment or 15 weeks after the experiment. To test formally for present bias we regress early payments on dummy variables for $t=5$ and $t=15$ as well as the price ratio while clustering standard errors at the individual level. ${ }^{23}$ Table 2 presents the results of these regressions. If the date of first payment is immediate rather than 5 or 15 weeks in the future, lower-score subjects

\footnotetext{
${ }^{21}$ Alert readers will note that equation (1) models demand for early versus late experimental payments in the same way economists typically model intertemporal consumption choices. Of course, if subjects choose total consumption according to (1) but have access to perfect capital markets, their demand for experimental payments will consist of corner solutions (i.e. either $X=0$ or $Y=0$ ) that maximize the market value of experimental payments. Effectively, subjects would behave as if the $U$ function had little or no curvature. We test this idea formally in Section 4.3 and argue that it may shed some light on the possible mechanisms behind our estimated treatment effects.

${ }^{22}$ Because we do not observe choices from a zero-interest budget and Figure 2 indicates substantial non-linearity in the demand curves, we used our structural model to estimate choices at $R=1$ to further test the prediction about income levels when $R=1$. We found strong support, for all combinations of delay length and whether the early payment occurs immediately. The minimum predicted zero-interest demand is $€ 9.32$ (S.E. $=0.25$ ).

${ }^{23} \mathrm{~A}$ regression approach is necessary because price ratios are not exactly balanced across the $t$ dimension.
} 
borrow significantly more of their endowment. High-score subjects do the same for only the 15 week delay.

Table 2 about here

Finally, we note that there are only small and statistically insignificant differences between the early payment choices of high- and lower-Baccalauréat-score participants in our overall sample which combines all treatments. Specifically, lower-score participants select a slightly higher overall level of early payment, and display slightly more present bias, but neither gap is significant at conventional levels. ${ }^{24}$ As the next section shows, however, this aggregate result obscures sizeable differences in the effects of treatment on the behavior of high- versus lower-score participants.

\subsection{Simple Estimates of Treatment Effects}

Our first look at the effects of the various treatments is non-parametric. Figure 3 presents the mean demand for early payments across the Baseline, Depletion, Placebo and Sugar treatments by Baccalauréat score. Since these comparisons are between individuals, the treatments are balanced with respect to prices, delays and start dates.

Figure 3 about here

Result 3 - For the lower test score sample, depletion, a sugared drink and a non-sugared drink all reduce the demand for early payment. All of these treatment effects are absent among participants with very high test scores.

The $p$-values in Figure 3 indicate that all three treatments reduce demand for early income amongst lower-score participants, with particularly strong sugar effects $(p=0.003)$ and depletion effects $(p=0.046)$. The placebo effect is significant $(p=0.093)$, but is almost half the magnitude of the sugar effect; the difference between the two effects is significant $(p=0.056)$, indicating that

\footnotetext{
${ }^{24}$ Averaged across all choices, lower-score participants allocate about $€ 0.70$ more experimental income $($ S.E. $=0.54$, clustered by individual) to the earlier payment date than high-score participants. This difference is not significant. We add interaction terms between the dummy variables for $t=5$ and $t=15$ and high-score as well as a high-score level effect into the present bias regressions from Table 2. The gap between early demand when $t=0$ versus $t=5$ is about $€ 0.31$ smaller for high-score participants, but this difference is not significant $(\mathrm{S}$.E. $=0.38)$. The signs and significances of the non-interacted dummies are unaffected.
} 
the sugar treatment had effects on choice above and beyond that of the placebo. ${ }^{25}$ On the other hand, only the sugar treatment affects the demand for early income significantly (and positively) of the high-score subjects $(p=0.082)$. This effect is not significantly different from the placebo effect at conventional levels $(p=0.143)$ however.

A final noteworthy finding in Figure 3 is that high- and lower-score subjects differ substantially in their Baseline choices. The difference of $€ 3.07$ between the groups' early payment demand in the Baseline is significant $(p=0.011)$. Recalling that there was no significant difference between high- and lower-score participants overall, this suggests that, in essence, our three interventions have the effect of narrowing the behavioral difference between high- and lower-score participants by reducing lower-scoring participants' demand for early income. The next result probes the sources of this difference-reducing effect further.

Result 4 - The negative effect of all three treatments on lower-score participants' demand for early payment is strongest in cases where the price of early income is high.

Figures A2 and A3 in Appendix plot the demand curves for early payments for each $(t, k)$ pair for lower-score and high-score participants, respectively. The lower-score participants exhibit a similar level of demand across all treatments at low price levels. As the price of early income rises, early payments decline more rapidly in the Depletion, Sugar, and Placebo treatments than in the Baseline. The high-score participants show a similar level of demand to the lower-score participants at low prices, but demand is highly price-sensitive in all four treatments. In this sense, the treatments appear to make the lower-score participants more price-sensitive, and thus more similar to the high-score participants' behavior.

To determine the statistical significance of the above effects, we define three price levels based on the relative value of early tokens. When early tokens are worth $€ 0.90$ or more we say the price is low, when they are worth between $€ 0.80$ and $€ 0.90$, we say the price is medium and when they are worth $€ 0.80$ or less, we say the price is high. ${ }^{26}$ Table 3 presents OLS regressions of early payment

\footnotetext{
${ }^{25}$ We use participants' estimates of the calories their beverage contained in order to ascertain whether this difference is due to psychology or physiology. Amongst lower-score subjects, there is no evidence that the magnitude of the Sugar-Placebo gap is affected by the beliefs about the drink or that beliefs themselves generate differences in demand.

${ }^{26}$ Note that this definition focuses on the most salient aspect of the price presented to the participants: the changing value of an early token within a particular choice screen $(t, k$ combination). Thus, the ranking is different than one
} 
demand on the treatment dummy variables split by price level. At medium and high prices all three treatments have significant effects for the lower-score group and the magnitude of the sugar effect is larger at high as opposed to low prices. The sugar effect is significantly greater than the placebo effect in the medium price condition $(p=0.003)$ and borderline significantly greater in the high price condition $(p=0.105)$. Column (3) suggests an elasticity-reducing effect of the Sugar treatment on the high-score subjects, but the effects are not statistically different from the Placebo effects in either medium or high price condition ( $p=0.132$ and $p=0.218$ respectively).

Table 3 about here

In sum, our nonparametric analysis shows that all three treatments (Depletion, Placebo and Sugar) reduce early demand among subjects with lower Baccalauréat test scores, who are more representative of the educated French population than our high-test score sample. This apparent increase in 'patience' occurs only when the price of early income is high, so the treatments effectively make lower-score subjects more price-sensitive and therefore their overall behavior more similar to our 'elite' sample.

\subsection{Treatment Effects in a Structural Model of Time Preferences}

To measure whether the treatments affected different aspects of participants' preferences, ${ }^{27}$ we now estimate a simple structural model of intertemporal preferences in which the treatments can affect each one of the fundamental utility parameters (specifically, their discount rate, present bias and intertemporal substitution parameters). One primary advantage of the CTB method is that it allows for the precise estimation of the parameters of structural models of intertemporal choice, even on the individual level. We will consider two types of structural treatment effects: aggregate and individual. Aggregate effects will compare one treatment-specific parameter estimate to another and individual effects will compare the set of individual-specific parameter estimates within one

based on annualized interest rate.

${ }^{27}$ For example, while reduced utility curvature (higher $\alpha$ ) is associated with higher price-sensitivity, it should also increase the response to $k$ (the gap between the payment dates). In general, because the demand functions implied by most theoretically interesting demand functions are nonlinear, the predicted marginal effects of each parameter depend on the levels of all the others, making simple regression tests only roughly informative about the effects of treatments on preference parameters. 
treatment to those from another. The two approaches yield similar results. As in section 4.2, splitting the sample by test score is essential for understanding the treatment effects.

We first provide a characterization of an individual's decision problem. Consider individual $i$ making decision $j$. Continue to denote $X$ as the number of tokens received at the earlier date and $Y$ the number at the later date. Individual $i$ is assumed to have power income utility (with exponent $\alpha$ ) that is additively separable across time periods in a $\beta$ - $\delta$ form (Laibson 1997; O'Donoghue and Rabin 1999). Choice $j$ is characterized by the price of sooner income, $R$, a delay between the two payment dates, $k$, and an indicator for whether or not the sooner date is today, $T$ (equal to 1 if $t$ $=0$, and 0 otherwise). As in equation (1), $M$ is the total number of tokens available. We suppose that subjects optimize in the following way: ${ }^{28}$

$$
\left(X_{i j}, Y_{i j}\right)=\underset{X, Y}{\arg \max } \quad X^{\alpha}+\beta^{T_{j}} \delta^{k_{j}} Y^{\alpha} \quad \text { subject to } \quad R_{j} X+Y \leq M .
$$

To identify preferences, we follow the approach of AS by applying non-linear least squares (NLS) to the demand function for sooner tokens, derived directly from equation 2. This approach yields the structural regression equation

$$
X_{i j}=\frac{M\left(\beta_{j}^{T} \delta_{j}^{k} R_{j}\right)^{\frac{1}{\alpha-1}}}{1+R_{j}\left(\beta_{j}^{T} \delta_{j}^{k} R_{j}\right)^{\frac{1}{\alpha 0-1}}}+\epsilon_{i j}
$$

To analyze and test treatment effects, we replace $\alpha$ with

$$
\alpha_{1}+\alpha_{2} D_{i}+\alpha_{3} P_{i}+\alpha_{4} S_{i}
$$

where $D, P$ and $S$ are treatment indicator variables, and make similar substitutions for $\beta$ and $\delta$. Instead of presenting results on $\delta$ itself, we use $r=\delta^{-365}-1$, the yearly discount rate equivalent, for ease of interpretation.

Setting out the structural form in (2)-(4) allows us to be more precise about how our manipulations of the cognitive and physiological environments affect subjects' intertemporal choices than

\footnotetext{
${ }^{28}$ Note that equation (1) implies that the set of available allocations is convex: that the tokens can be infinitely divided. While we offer subjects 17 possible allocations along the budget frontier rather than an infinite number, we argue that this is a suitable approximation to convexity. Andreoni, Kuhn and Sprenger (2013) perform a similar exercise with 6 allocations and find no evidence of bias due to discretization.
} 
the more generic notions of 'impatience' or 'impulsivity'. For example, if a treatment raises $r$, it should increase subjects' demand for early rewards relative to late rewards regardless of the amount of delay between the two payment dates, and regardless of whether the early period corresponds to the date of the experiment or a future date. If a treatment lowers $\beta$ (the present bias parameter) below 1, it increases subjects' attraction only to rewards that are received on the date of the experiment; high levels of present bias (low values of $\beta$ ) generate temporal inconsistencies in choices that may correspond to psychological notions of a failure of willpower. Finally, if treatments increase $\alpha$, they make subjects more responsive to the costs of early income, which under some conditions (i.e. access to capital markets) might also be interpreted as an 'improvement' in the effectiveness of subjects' decisions. All three notions are conflated in the more amorphous notion of willpower that is often used to interpret experimental results on the effects of cognitive depletion.

We first estimated equation (3) without treatment effects, following our modification of the CTB technique introduced by AS in the calibration of prices. Our estimate of the aggregate yearly discount rate is $21.8 \%$ for lower-score types $($ S.E. $=5.9 \%)$ and $21.0 \%$ for high-score types $($ S.E. $=4.1 \%) .{ }^{29}$ Our estimates of the $\beta$ parameter are $0.976($ S.E. $=0.008)$ for lower-score and 0.988 (S.E. $=0.007)$ for high-score, with both values significantly less than 1 ( $p=0.005$ and $p=0.086$, respectively). Thus, in contrast to AS who estimate $\beta=1.007$ (S.E. $=0.006$ ), we find evidence of present bias in the $\beta-\delta$ form. ${ }^{30}$ Lastly, we estimate a lower degree of curvature: $\alpha=0.922$ (S.E. $=0.008)$ for lower-score and $0.942($ S.E. $=0.005)$ for high-score individuals as opposed to 0.897 $($ S.E. $=0.009)$ in AS.

Result 5 - The treatment effects on the structural parameters are concentrated on $\alpha$, the utility function curvature parameter. The magnitudes are economically significant at interest rates that correspond to predatory credit instruments.

Table 4 presents estimates of treatment effects on the parameters of a common utility function, shared by all individuals in each estimation sample. The treatment effects only show up as signif-

\footnotetext{
${ }^{29}$ The corresponding specification from AS (Table 2, column (3)) estimates a rate of $37.7 \%$ with a standard error of $8.7 \%$. Because our max time horizon is slightly longer, we would expect a slightly lower estimate of the rate if individuals display some insensitivity to the exactness of dates far in the future.

${ }^{30}$ While this magnitude of present bias over pure allocations of money is not economically meaningful in our experiment, a $3 \%$ distortion of preferences could be very important for major financial decisions.
} 
icant for utility curvature. Both Drink treatments significantly decrease lower-score curvature, but the effect is significantly larger for the sugared drink $(p=0.020)$. While the high-score curvature increase is significant only for the Sugar treatment, this effect is not significantly different from the effect of the Placebo treatment $(p=0.167)$. In contrast to the simple estimates of treatment effects, we do not see a significant effect of the Depletion treatment on the three utility parameters, taken individually, amongst the lower-score group. However, depletion effects on both the present bias and the curvature parameters have $p$-values below 0.15 and the joint hypothesis that these effects are zero is rejected $(p=0.088)$. The two Drink treatments have significant joint effects as well. All three effects on parameters are jointly different from zero in the Placebo treatment $(p=0.021)$ and in the Sugar treatment $(p=0.001)$ in the lower-score sample. The Sugar treatment also has a significant effect on all three parameters in the opposite direction in the high-score sample $(p=$ $0.033)$.

Table 4 about here

The fact that the treatment effects operate through utility curvature is consistent with Result 4: they make the lower-score individuals more price sensitive. In the limiting case where the utility function has no curvature, optimal choices move from one corner to the other as prices change. The less curvature the function has, the closer we are to this case, and the more responsive individuals will be. To illustrate this, consider subjects from our experiment making a decision about taking a 2-week payday loan against a $€ 1000$ paycheck that comes with a $15 \%$ charge (APR $=390 \%)$. Roughly, the optimal loan for a lower-score, Baseline treatment individual is $€ 310$, which results in a $€ 60$ charge. Holding the discount and present-bias factors constant ${ }^{31}$ and switching to the Depletion curvature estimate reduces the loan to $€ 220$ (charge of $€ 40$ ), the Placebo curvature estimate to $€ 140$ (charge of $€ 20$ ) and the Sugar curvature estimate to $€ 60$ (charge of $€ 10$ ).

Turning now to our method that allows each subject to have his/her own set of utility parameters, $(\alpha, \beta$ and $\delta$ ), we make a couple of adaptations that are dictated by the estimation results. First, we drop 21 individuals who lack enough choice variation for the successful estimation of the parameters. Second, because using the NLS technique with only 45 observations per subject

\footnotetext{
${ }^{31} \mathrm{We}$ do this to recognize that the effects we find on $r$ and $\beta$ are not estimated precisely. If we do take these effects into account however, the gap between Baseline and the other treatments is larger. While the optimal loan remains at $€ 310$ in Baseline, it is $€ 160$ in Depletion, $€ 90$ in Placebo and $€ 30$ in Sugar.
} 
delivers some extreme outlying estimates, we trim the sample at the 5th and 95th percentiles of the distribution of all three parameter estimates. This excludes 24 more subjects, leaving a sample of 104. Of the 45 excluded subjects, 28 are from the lower-score sample and 17 are from the high-score sample.

Table 5 reports estimates of treatment effects on the individual-specific parameters using quantile regressions at the median value of the estimate distribution. Specifically, for each of the three parameters, we estimated a median regression on 104 observations in which the participant's parameter estimate was the dependent variable and the three treatment indicators were the only regressors. Standard errors for these estimates are obtained via bootstrap with 1000 replications. The estimated individual effects are largely consistent with the aggregate effects. Both drinks significantly decrease curvature in the lower-score sample. The depletion effect on curvature in the lower-score sample is now marginally significant; whereas it was marginally insignificant in the aggregate test. The Depletion and Sugar treatments appear to have minor present-bias inducing effects for the high-score group.

Table 5 about here

All three treatments increase the amount of deferred income for the lower-score individuals by reducing utility curvature such that budgets featuring above-market interest rates generate large differences in allocations versus the Baseline. There exists some evidence that the Sugar treatment had stronger effects than the Placebo treatment.

\subsection{Robustness}

If time preferences are indeed dependent to a degree on physiological conditions, it would be encouraging if our treatment effects were moderated by the condition in which individual subjects entered the lab. While subjects were asked not to eat or drink for at least three hours prior to the experiment, our survey indicated that there was substantial variation in the degree of adherence to this request. Almost $19 \%$ of individuals had not eaten since the day before the experiment and around $7 \%$ had eaten within the three hour window prior to the experiment. We expect that subjects should have been more susceptible to the interventions the longer they went without eating. Table 
6 presents treatment effect regressions on demand for early payment with interactions between the Depletion, Placebo and Sugar variables with the number of hours since last meal.

Consistent with our baseline results, we find no significant treatment effects on the high-scoring subjects; this group's decisions are also unaffected by the amount of elapsed time since their last meal. Lower-scoring subjects, on the other hand, become less patient as the time since their last meal increases; this behavior evokes Danziger et al.'s (2011) parole board members. Also, as predicted, lower-scoring subjects' sensitivity to all three of our interventions increases with elapsed time since their last meal. ${ }^{32}$ While this may not be surprising for the drink treatments, it is perhaps noteworthy that "depleting" our subjects via the Stroop test also has a larger patience-enhancing effect on hungry than on recently-nourished subjects. This finding reinforces our suggestion that engaging in a novel but cognitively demanding task can actually (at least temporarily) improve a vulnerable subject's ability to focus on economic decisions.

Table 6 about here

To rule out mood or affect as potential drivers of our sugar or placebo effects, we use the elicited mood and beverage enjoyment data from the post-drink surveys (Drink treatments) and entry surveys (Baseline treatment). ${ }^{33}$ First and foremost, mood is not predictive of demand in our experiment. Second, we use a specification identical to our hours-since-last-meal analysis, but replace that variable with the self-reported mood variable, and exclude individuals from the Depletion treatment (since their mood elicitation took place prior to the Stroop task). Results are in Appendix Tables A2 and A3. We again find no substantive evidence that mood is related to demand for lower-score participants, ${ }^{34}$ and weak evidence that high-score participants in the placebo condition may demand smaller early payments as their mood improves. ${ }^{35}$

To add credence to our use of the Baccalauréat exam score as a measure of cognitive ability, we present treatment effect estimates split by CRT performance instead of by Baccalauréat score. ${ }^{36}$ As noted, these estimates should be interpreted with caution since the treatments may have affected the

\footnotetext{
${ }^{32}$ Note that the uninteracted treatment effects no longer enter as significant because they are estimates specific to the intercept where the time since last meal is zero.

${ }^{33}$ Both mood and beverage enjoyment are elicited as numbers from 1 (negative) to 10 (positive).

${ }^{34}$ The same is true of elicited beverage enjoyment.

${ }^{35}$ Attempts to replicate the Ifcher and Zarghamee (2011) result by using our treatment variables as instruments for mood fail due to a lack of relevance: our treatments do not appear to affect mood.

${ }^{36}$ As mentioned earlier, CRT and Baccalauréat performance are positively and significantly correlated.
} 
subjects' CRT performance, just as they affected the subjects' performance in the time-preference task. That said, consistent with our results using the Baccalauréat, we find significant effects of the treatments on time preferences only for those who failed to answer a single CRT question correctly (slightly more than $70 \%$ of these individuals are in the lower-score group). Results are presented in Table 7.

Table 7 about here

Finally, we note that while our structural demand equation (3) is for a continuous measure of early income, our experimental subjects could choose only integer numbers of tokens; relatedly, optimal choices in (3) approach corner solutions as the degree of preference curvature approaches zero ( $\alpha$ approaches one). ${ }^{37}$ To check whether this affects our estimates, we estimated specifications with three options: 1) sooner corner, 2) interior and 3) later corner using a multinomial logit specification. Results are found in Appendix Table A4. Reassuringly, in the lower-score sample, the probability of choosing the sooner corner is significantly lower in the Depletion and Sugar treatments and the probability of choosing the later corner is significantly greater in the Depletion, Sugar and Placebo treatments.

\section{Discussion and Conclusion}

This paper studies the effects of experimental manipulations of prior cognitive demands and sugar consumption on time preferences. A key innovation of our approach is that an explicit model of intertemporal choice allows us to distinguish three conceptually distinct aspects of 'patience' (the tendency to defer income) that might be affected by the cognitive and physiological environment: discount rates, present bias, and price sensitivity. We find that intertemporal choices are sensitive to transient features of the environment, but whether and how depends critically on cognitive ability. Indeed, exposure to the Stroop task prior to the elicitation of time preferences increases mean patience by making lower-test-score participants more responsive to high prices for early income. While this may be surprising at first pass, there are some reasonable explanations. We

\footnotetext{
${ }^{37}$ In fact, around $75 \%$ of choices in our experiment are at corners, reflecting the relatively low degree of estimated preference curvature among our subjects, especially at high cognitive ability levels and in the presence of interventions that reduce curvature.
} 
first note that our time preference elicitation task differs substantially from the types of impulsecontrol tasks typically studied in psychology lab experiments, and from our motivating example of the Israeli parole board. The judges make a series of choices between two options all day long, whereas our subjects face a totally unrelated task that necessitates impulse control prior to the time preference elicitation. It seems like the Stroop task primed the subjects to resist impulsive inclinations on the subsequent task. Thus, our 'depletion' results suggest that priming consumers to exercise willpower and pay close attention may generate more effective intertemporal choices. This result is echoed in Burger, Charness and Lynham (2011), who showed that cognitive depletion improves long-run task completion rates. It is also consistent with Tuk, Trampe and Warlop's (2011) finding that increased urination urgency associated with a full bladder improves subjects' ability to resist more immediate temptations in monetary decision making. Turning to our drink treatments, drinking either the placebo beverage or the sugared beverage ten minutes prior to the time task also increases patience, and does so by raising lower-test-score subjects' sensitivity to high prices. The magnitude of the sugar effect is significantly greater than the magnitude of the placebo effect. The finding that the sugared beverage has a positive effect is consistent with both the Energy and Motivational models of self-control. The finding that the placebo beverage does the same appears to be inconsistent with both. One caveat to this is that the placebo did contain a very small amount of sugar. While this amount is not enough to meaningfully affect blood glucose levels, its presence could have activated the area of the brain that is highly sensitive to rewards and incentives, consistent with Molden et al.'s (2012) and Sanders et al.'s (2012) evidence that rinsing one's mouth with a sugared beverage has similar effects to consuming it.

Another potential explanation of our estimated 'drink' effects is a substitution between primary and secondary rewards. Indeed, the drink - whether sugared or not - could be perceived as a reward, since participants were required not to eat or drink for three hours prior to the experiment. ${ }^{38}$ Consistent with the notion of a common neural value of rewards (see Dreher 2009), receiving a drink as a reward may reduce participants' desire for an immediate secondary reward (i.e. money on the day of the experiment). One difficulty with this hypothesis, however, is that the

\footnotetext{
${ }^{38}$ Our reading of the existing experiments on sucrose drinks' effects on willpower suggests that, in contrast to us, many of the experiments did not ask subjects to refrain from food or drink during a period before the experiment (for example, studies 7-9 in Gailliot et al. (2007) do not mention that subjects were asked to abstain before the experiment). This could explain the substantial placebo effects we observe. This does not apply to Sanders et al. (2012).
} 
drinks should act primarily on subjects' present bias, not on their price-sensitivity as we observe. Alternatively, the drinks could satisfy a different biological need than the need for energy (i.e. quenching thirst). Relieving subjects' thirst may improve their ability to concentrate on the time choice task compared with the Baseline treatment. Unlike the primary reward hypothesis, this mechanism seems more consistent with the fact that the treatments operate via price-sensitivity rather than present bias or discount rates.

Finally, as already noted, a more 'economic' mechanism that could explain our results relates to a recent critique of time-preference elicitation experiments (Chabris, Laibson and Schuldt 2008), namely that the choices of well-informed, alert agents with access to capital markets in those experiments should be more informative about their capital market options than their preference parameters. Specifically, in our convex environment such subjects should pick corner solutions that depend on whether the gross interest rate on a particular choice is above or below their outside rate option. While our Drink and Depletion treatments cannot, of course, affect our participants' capital market options, it is possible that they affected the extent to which participants had the mental energy or focus to incorporate those options into their decisions. Such increased sensitivity to outside rates would make our estimated indifference curves less convex (linear in the extreme), and thus be reflected in our estimates of $\alpha .^{39}$

The primary lesson of our study is that transient cognitive factors we rarely consider in economics can substantially alter economic decision making. The magnitudes of our effects are considerable: According to our estimates, lower-score subjects in our Baseline Treatment would demand an advance of $€ 310$ when offered a 2 -week payday loan that comes with a $15 \%$ charge $(\mathrm{APR}=390 \%)$, for a total loan charge of $€ 60$. If our experimental manipulations affect preference curvature as estimated in Section 4.3, our Depletion treatment reduces the desired loan to $€ 220$ (charge of $€ 40$ ). The Placebo treatment further reduces loan demand to $€ 140$ (charge of $€ 20$ ) and the Sugar treatment to $€ 60$ (charge of $€ 10$ ).

Payday loans such as the above are considered by many to be 'predatory' in that their shortterm nature takes advantage of scope insensitivity in interest rates to charge astronomical rates. In these situations, our finding that all of the treatment effects operate through the curvature of

\footnotetext{
${ }^{39}$ Carvalho, Prina and Sydnor (2013) use a similar elicitation to ours to study the effects of randomly providing individuals with a savings account on time preferences. Echoing our results, their treatment effects are concentrated on utility curvature, suggesting increased sensitivity of choices to market options.
} 
the within-period utility function (which is also the intertemporal elasticity of substitution and the main determinant of the price-elasticity) indicates that unless consumers are highly attuned to their task at hand, they may ignore substantial price differences across assets or credit payments. This emphasizes the need to both help consumers make active and aware choices whenever possible and be vigilant in preventing firms from purposefully taking advantage of compromising cognitive environments. ${ }^{40}$ For those concerned about the external validity of our experimental measures, we point to existing literature that demonstrates a strong relationship between experimentally elicited impatience and wealth and health investment (Hastings and Mitchell, 2011), present-bias and credit card debt (Meier and Sprenger, 2010) and time discounting and credit scores (Meier and Sprenger, 2012).

Finally, we note that while the above effects are largely absent among subjects with very high cognitive abilities (corresponding to the top decile of French high school graduates), our main results pertain to a subject pool whose cognitive ability is still well above the national mean (representing about the 50th-90th percentiles of high school graduates). This suggests that sensitivity of economic choices to transitory environmental features is likely widespread in most populations of interest.

\footnotetext{
${ }^{40}$ Gneezy and Imas (2013) demonstrate in a laboratory setting both that emotionally compromised individuals make poor strategic decisions and that individuals will ex-ante choose to compromise their opponents' emotional environments to precipitate such poor decisions.
} 


\section{References}

[1] S. Andersen, G.W. Harrison, M.I. Lau, and E.E. Rutström. Eliciting risk and time preferences. Econometrica, 76(3):583-618, 2008.

[2] J. Anderson, S. Burks, C. DeYoung, and A. Rustichini. Toward the integration of personality theory and decision theory in the explanation of economic behavior. Unpublished manuscript, University of Minnesota, 2011.

[3] J. Andreoni, M.A. Kuhn, and C. Sprenger. On measuring time preferences. Working paper, UC San Diego, 2013.

[4] J. Andreoni and C. Sprenger. Estimating time preferences from convex budgets. American Economic Review, 102(7):3333-3356, 2012.

[5] J. Andreoni and C. Sprenger. Risk preferences are not time preferences. American Economic Review, 102(7):3357-3376, 2012.

[6] R.F. Baumeister, M.T. Gailliot, C.N. DeWall, and M. Oaten. Self-regulation and personality: How interventions increase regulatory success, and how depletion moderates the effects of traits on behavior. Journal of Personality, 74(6):1773-1801, 2006.

[7] S. Benartzi and R.H. Thaler. Naïve diversification strategies in defined contribution plans. American Economic Review, 91(1):79-98, 2001.

[8] D.J. Benjamin, S.A. Brown, and J.M. Shapiro. Who is "behavioral"? cognitive ability and anomalous preferences. Journal of the European Economic Association, 2013. Forthcoming.

[9] D. Benton, D.S. Owens, and P.Y. Parker. Blood glucose influences memory and attention in young adults. Neuropsychologia, 32(5):595-607, 1994.

[10] J. Beshears, J.J. Choi, D. Laibson, and B.C. Madrian. How does simplified disclosure affect individuals' mutual fund choices? In D.A. Wise, editor, Exploration in the Economics of Aging. University of Chicago Press, 2011. 
[11] J. Beshears, J.J. Choi, D. Laibson, and B.C. Madrian. Simplification and saving. Journal of Economic Behavior and Organization, 2013. Forthcoming.

[12] A. Bucciol, D. Houser, and M. Piovesan. Temptation and productivity. Journal of Economic Behavior and Organization, 78(1):126-136, 2011.

[13] A. Bucciol, D. Houser, and M. Piovesan. Temptation at work. Working paper No. 11-090, Harvard Business School, 2011.

[14] N. Burger, G. Charness, and J. Lynham. Field and online experiments on self-control. Journal of Economic Behavior and Organization, 77(3):393-404, 2011.

[15] M. Callen, M. Isaqzadeh, J.D. Long, and S. Sprenger. Violent and trauma and risk preference: Experimental evidence from Afghanistan. 2013. Forthcoming.

[16] G.D. Carroll, J.J. Choi, D. Laibson, B.C. Madrian, and A. Metrick. Optimal defaults and active choices. Quarterly Journal of Economics, 124(4):1639-1674, 2009.

[17] L. Carvalho, S. Prina, and J. Sydnor. The effects of savings on risk-taking and intertemporal choice behavior: Evidence from a randomized experiment. Working paper, 2013.

[18] B.J. Casey, L.H. Somerville, I.H. Gotlib, O. Ayduk, N.T. Franklin, M.K. Askren, J. Jonides, M.G. Berman, N.L. Wilson, T. Teslovich, G. Glover, V. Zayas, W. Mischel, and Y. Shoda. Behavioral and neural correlates of delay of gratification 40 years later. Proceedings of the National Academy of Sciences, 108(36):14998-15003, 2011.

[19] C.F. Chabris, D. Laibson, and J.P. Schuldt. Intertemporal choice. In S. Durlauf and L. Blume, editors, New Palgrave Dictionary of Economics. Palgrave Macmillan, 2008.

[20] E.S. Chambers, M.W. Bridge, and D.A. Jones. Carbohydrate sensing in the human mouth: Effects on exercise performance and brain activity. Journal of Physiology, 587(8):1779-1794, 2009.

[21] G. Charness and M. Rabin. Understanding social preferences with simple tests. Quarterly Journal of Economics, 117(3):817-869, 2002. 
[22] J.J. Choi, D. Laibson, and B.C. Madrian. Reducing the complexity costs of 401(k) participation through quick enrollment. In D.A. Wise, editor, Developments in the Economics of Aging. University of Chicago Press, 2009.

[23] S. Danziger, J. Levav, and L. Avanaim-Pesso. Extraneous factors in judicial decisions. Proceedings of the National Academy of Sciences, 108(17):6889-6892, 2011.

[24] S. DellaVigna, J.A. List, and U. Malmendier. Testing for altruism and social pressure in charitable giving. Quarterly Journal of Economics, 127(1):1-56, 2012.

[25] C.N. DeWall, R.F. Baumeister, M.T. Gailliot, and J.K Maner. Depletion makes the heart grow less helpful: Helping as a function of self-regulatory energy and genetic relatedness. Personality and Social Psychology Bulletin, 34(12):1653-1662, 2008.

[26] C.N. DeWall, R.F. Baumeister, T.F. Stillman, and M.T. Gailliot. Violence restrained: Effects of self-regulation and its depletion on aggression. Experimental Social Psychology, 43(1):62$76,2007$.

[27] D.L. Dickinson and T. McElroy. Rationality around the clock: Sleep and time-of-day effect on guessing game responses. Economics Letters, 108(2):245-248, 2010.

[28] T. Dohmen, A. Falk, D. Huffman, and U. Sunde. Are risk aversion and impatience related to cognitive ability? American Economic Review, 100(3):1238-1260, 2010.

[29] D. Dotter. Breakfast at the desk: The impact of universal classroom breakfast programs on academic performance. Working paper, UC San Diego, 2013.

[30] J.C. Dreher. Decomposing brain signals involved in value-based decision-making. In J.C. Dreher and L. Tremblay, editors, Handbook of Reward and Decision Making. Burlington: Academic Press, 2009. 137-163.

[31] S. Frederick. Cognitive reflection and decision making. Journal of Economic Perspectives, 19(4):25-42, 2005.

[32] D.C. Funder and J. Block. The role of ego-control, ego-resiliency, and iq in delay of gratification in adolescence. Journal of Personality of Social Psychology, 57(6):1041-1050, 1989. 
[33] M.T. Gailliot and R.F. Baumeister. The physiology of willpower: Linking blood glucose and self-control. Personality and Social Psychology Review, 11(4):303-327, 2007.

[34] M.T. Gailliot, R.F. Baumeister, C.N. DeWall, J.K Maner, E.A. Plant, D.M. Tice, L.E. Brewer, and B.J. Schmeichel. Self-control relies on glucose as a limited energy source: Willpower is more than a metaphor. Journal of Personality and Social Psychology, 92(2):325-336, 2007.

[35] M.T. Gailliot, B.M. Peruche, E.A. Plant, and R.F. Baumeister. Stereotypes and prejudice in the blood: Sucrose drinks reduce prejudice and stereotyping. Journal of Experimental Social Psychology, 45(1):288-290, 2009.

[36] U. Gneezy and A. Imas. Materazzi effect: On the strategic use of anger. Working paper, UC San Diego, 2013.

[37] B. Greiner. An online recruitment system for economic experiments. Forschung und wissenschaftliches Rechnen, 63:79-93, 2004.

[38] G.W. Harrison, M.I. Lau, and M.B. Williams. Estimating individual discount rates in denmark: A field experiment. American Economic Review, 92(5):1606-1617, 2002.

[39] J.S. Hastings and O.S. Mitchell. How financial literacy and impatience shape retirement wealth and investment behaviors. Working paper, NBER No. 16740, 2011.

[40] D. Houser, D.H. Reiley, and M.B. Urbancic. Checking out temptation: A natural experiment with purchases at the grocery register. Discussion paper, ICES George Mason University, 2008.

[41] J. Ifcher and H. Zarghamee. Happiness and time preference: The effect of positive affect in a random-assignment experiment. American Economic Review, 101(7):3109-3129, 2011.

[42] C. Kirby, G. Winston, and M. Santiesteban. Impatience and grades: Delay-discount rates correlate negatively with college gpa. Learning and Individual Differences, 15(3):213-222, 2005.

[43] M.L. Kringelbach. Food for thought: Hedonic experience beyond homeostasis in the human brain. Neuroscience, 126(4):807-819, 2004. 
[44] D. Laibson. Golden eggs and hyperbolic discounting. Quarterly Journal of Economics, 112(2):443-477, 1997.

[45] S. Luo, G. Ainslie, and J. Monterosso. The behavioral and neural effect of emotional primes on intertemporal decisions. Social, Cognitive and Affective Neuroscience, 2013. Forthcoming.

[46] C.M. MacLeod. Half a century of research on the stroop effect: An integrative review. Psychological Bulletin, 109(2):163-203, 1991.

[47] N.L. Mead, R.F. Baumeister, F. Gino, M.E. Schweitzer, and D. Ariely. Too tired to tell the truth: Self-control resource depletion and dishonesty. Journal of Experimental Social Psychology, 45(3):594-597, 2009.

[48] S. Meier and C. Sprenger. Present-biased preferences and credit card borrowing. American Economic Journal: Applied Economics, 2(1):193-210, 2010.

[49] S. Meier and C. Sprenger. Time discounting predicts creditworthiness. Psychological Science, 23(1):56-58, 2012.

[50] W. Mischel, E.B. Ebbesen, and A. Raskoff Zeiss. Cognitive and attentional mechanisms in delay of gratification. Journal of Personality and Social Psychology, 21(2):204-218, 1972.

[51] W. Mischel, Y. Shoda, and M.L. Rodriguez. Delay of gratification in children. Science, 244:933-938, 1989.

[52] D.C. Molden, C.M. Hui, A.A. Scholer, B.P. Meier, E.E. Noreen, P.R. D'Agostino, and V. Martin. Motivational versus metabolic effects of carbohydrates on self-control. Psychological Science, 23(10):1137-1144, 2012.

[53] M.R. Muraven and R.F. Baumeister. Self-regulation and depletion of limited resources: Does self-control resemble a muscle? Psychological Bulletin, 126(2):247-259, 2000.

[54] T. O’Donoghue and M. Rabin. Doing it now or later. American Economic Review, 89(1):103124, 1999. 
[55] E. Ozdenoren, S.W. Salant, and D. Silverman. Willpower and the optimal control of visceral urges. Journal of the European Economic Association, 10(2):342-368, 2012.

[56] H.E. Ryder. Heterogeneous time preferences and the distribution of wealth. Mathematical Social Sciences, 9(1):63-76, 1985.

[57] M.A. Sanders, S.D. Shirk, C.J. Burgin, and L.L. Martin. The gargle effect: Rinsing the mouth with glucose enhances self control. Psychological Science, 23(12):1470-1472, 2012.

[58] Y. Shoda, W. Mischel, and P.K. Peake. Predicting adolescent cognitive and self-regulatory competencies from preschool delay of gratification: Identifying diagnostic conditions. Developmental Psychology, 26(6), 1990.

[59] J.R. Stroop. Studies of interference in serial verbal reactions. Journal of Experimental Psychology, 18(6):643-662, 1935.

[60] R.H. Thaler and S. Benartzi. Save more tomorrow ${ }^{T M}$ using behavioral economics to increase employee saving. Journal of Political Economy, 112:S164-S187, 2004.

[61] M.A. Tuk, D. Trampe, and L. Warlop. Inhibitory spillover: Increased urination urgency facilitates impulse control in unrelated domains. Psychological Science, 22(5):627-633, 2011.

[62] K.A. Wesnes, C. Pincock, D. Richardson, G. Helm, and S. Hails. Breakfast reduces declines in attention and memory over the morning in schoolchildren. Appetite, 41(3):329-331, 2003. 
Table 1: Experimental Design

(1) (2)

(3)

(4)

(5)

$\begin{array}{lccccc}\text { Baseline } & \text { Entry survey } & \text { Rest } & \begin{array}{c}\text { Time preference } \\ \text { task }\end{array} & \text { Stroop task } & \text { Exit survey } \\ \text { Depletion } & \text { Entry survey } & \text { Rest } & \text { Stroop task } & \begin{array}{c}\text { Time preference } \\ \text { task }\end{array} & \text { Exit survey } \\ & & & & & \end{array}$

Placebo Sugar-free drink \& $\quad$ Rest $\quad$ Time preference $\quad$ Stroop task $\quad$ Exit survey Entry survey task

$\begin{array}{llllll}\text { Sugar } & \text { Sugared drink \& } & \text { Rest } & \text { Time preference } & \text { Stroop task } & \text { Exit survey }\end{array}$

Entry survey task




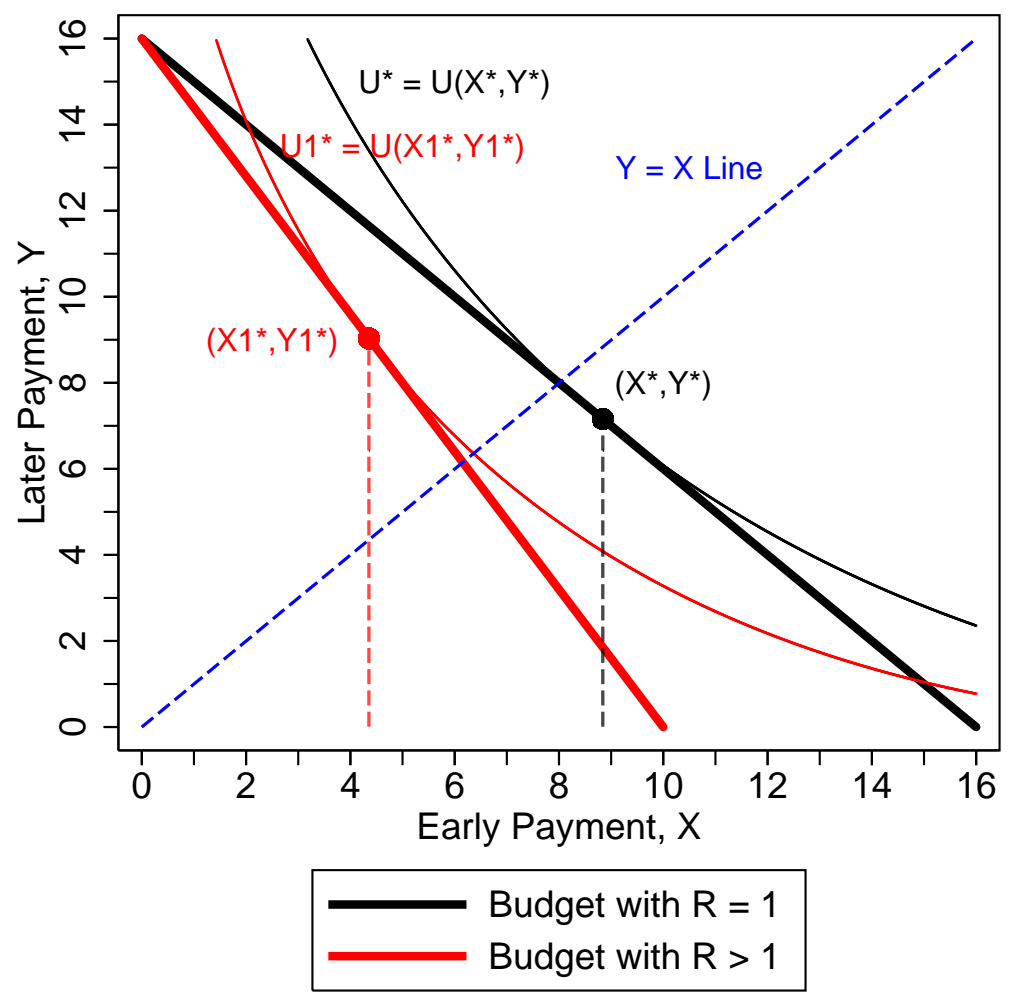

Figure 1: Predicted Behavior 


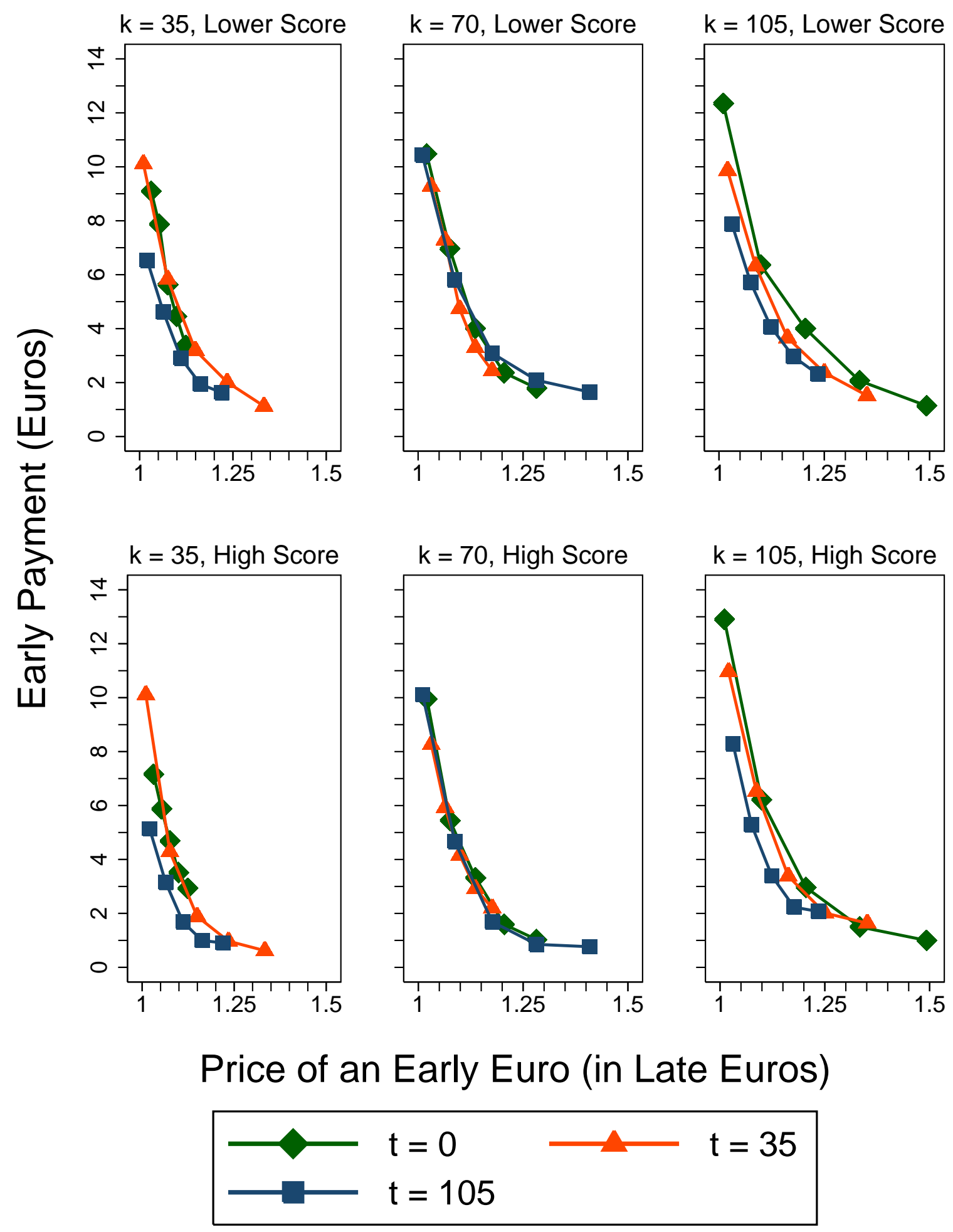

Figure 2: Demand Functions by Date of Early Payment, $t$, All Treatments 
Table 2: Effect of Start Date, $t$, on Early Payment Demand

\begin{tabular}{lccc} 
& \multicolumn{3}{c}{ Estimation Sample } \\
\hline & All Subjects & Lower-Score & High-Score \\
\hline Constant $(t=0, R=1)$ & $(1)$ & $(2)$ & $(3)$ \\
& $(0.437)$ & $(0.608)$ & $(0.627)$ \\
$1(t=5$ weeks $)$ & $-0.521^{* * *}$ & $-0.678^{* *}$ & -0.367 \\
& $(0.192)$ & $(0.264)$ & $(0.278)$ \\
$1(t=15$ weeks $)$ & $-1.324^{* * *}$ & $-1.308^{* * *}$ & $-1.340^{* * *}$ \\
& $(0.286)$ & $(0.409)$ & $(0.403)$ \\
Normalized Price Ratio $(R-1)$ & $-21.365^{* * *}$ & $-21.535^{* * *}$ & $-21.197^{* * *}$ \\
& $(1.197)$ & $(1.723)$ & $(1.675)$ \\
Clusters & & & \\
Observations & 149 & 74 & 75
\end{tabular}

${ }^{*} p<0.10,{ }^{* *} p<0.05,{ }^{* * *} p<0.01$

Standard Errors in parentheses, clustered by individual. 45 observations (budgets) per cluster. 


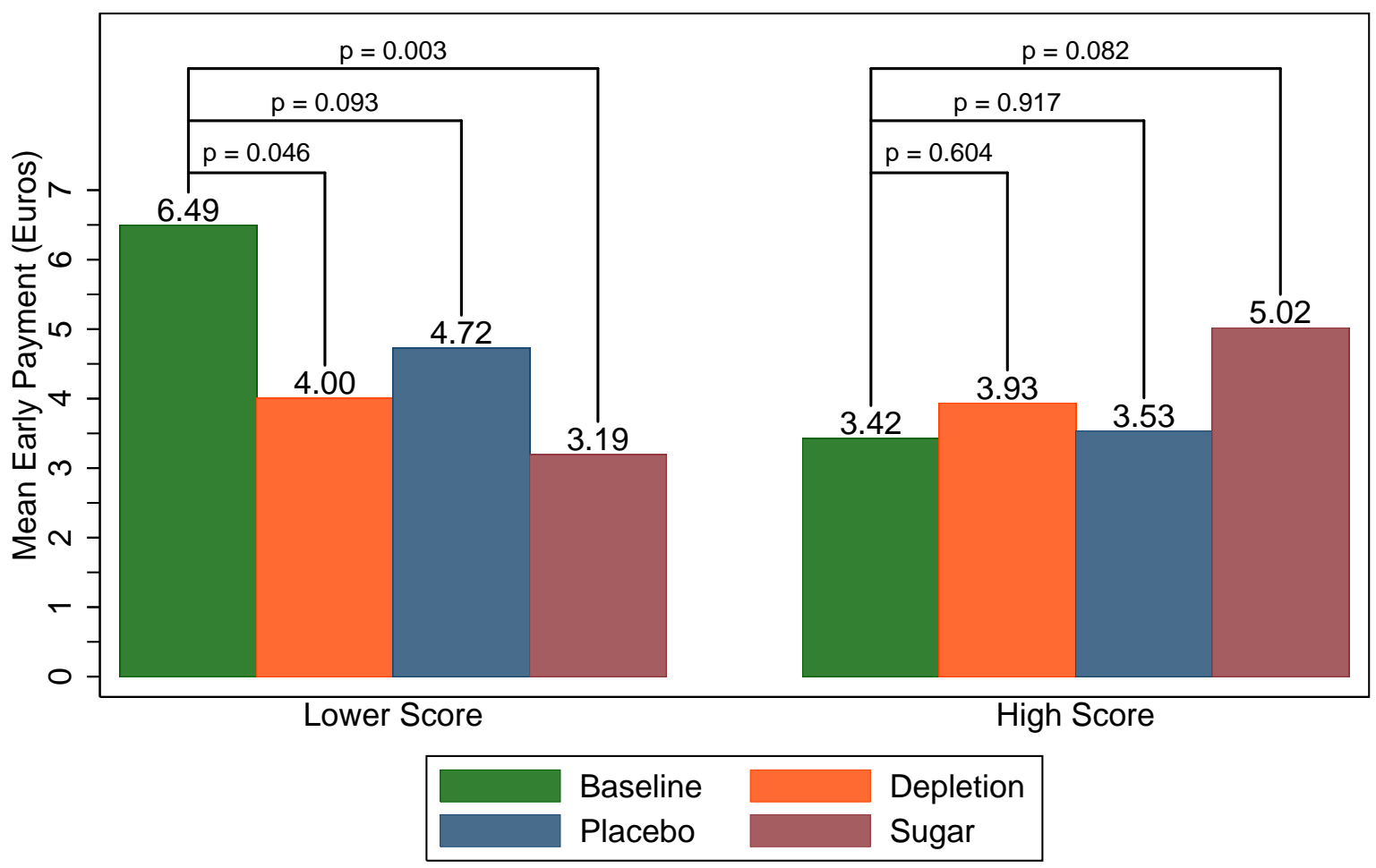

Figure 3: Mean Demand by Treatment

$p$-values are generated from regressions of the chosen early payment on treatment status with standard errors clustered at the individual level. The regression is run separately for lower- and high-score subjects. Each individuals makes 45 decisions, leaving us with a sample size of 3330 (74 clusters) in the lower-score group and 3365 (75 clusters) in the high-score group. An approach that collapses the data to individual-level means yields similar results. 
Table 3: Treatment Effect on Early Payment Demand by Price Level Estimation Sample

\begin{tabular}{|c|c|c|c|}
\hline & All Subjects & Lower-Score & High-Score \\
\hline & (1) & (2) & (3) \\
\hline Constant (Low price, Baseline) & $\begin{array}{c}7.976 \\
(0.803)\end{array}$ & $\begin{array}{c}8.809 \\
(1.036)\end{array}$ & $\begin{array}{c}6.449 \\
(1.146)\end{array}$ \\
\hline Low price $X$ Depletion & $\begin{array}{l}-1.778 \\
(1.093)\end{array}$ & $\begin{array}{l}-2.585 \\
(1.590)\end{array}$ & $\begin{array}{c}-0.276 \\
(1.460)\end{array}$ \\
\hline Low price X Placebo & $\begin{array}{c}-0.865 \\
(1.074)\end{array}$ & $\begin{array}{c}-0.944 \\
(1.316)\end{array}$ & $\begin{array}{c}-0.492 \\
(1.703)\end{array}$ \\
\hline Low price $X$ Sugar & $\begin{array}{c}-0.530 \\
(1.073)\end{array}$ & $\begin{array}{l}-2.569 \\
(1.567)\end{array}$ & $\begin{array}{c}1.444 \\
(1.433)\end{array}$ \\
\hline Medium price & $\begin{array}{c}-4.423^{* * *} \\
(0.534)\end{array}$ & $\begin{array}{c}-3.848^{* * *} \\
(0.645)\end{array}$ & $\begin{array}{c}-5.477^{* * *} \\
(0.876)\end{array}$ \\
\hline Medium price X Depletion & $\begin{array}{l}-1.287 \\
(1.862)\end{array}$ & $\begin{array}{c}-2.559^{* *} \\
(1.171)\end{array}$ & $\begin{array}{c}1.171 \\
(0.844)\end{array}$ \\
\hline Medium price X Placebo & $\begin{array}{c}-1.416^{*} \\
(0.793)\end{array}$ & $\begin{array}{c}-2.578^{* *} \\
(1.040)\end{array}$ & $\begin{array}{c}0.789 \\
(0.754)\end{array}$ \\
\hline Medium price X Sugar & $\begin{array}{c}-1.194 \\
(0.803)\end{array}$ & $\begin{array}{c}-4.321^{* * *} \\
(0.943)\end{array}$ & $\begin{array}{l}2.024^{* *} \\
(0.657)\end{array}$ \\
\hline High price & $\begin{array}{c}-5.764^{* * *} \\
(0.739)\end{array}$ & $\begin{array}{c}-5.550^{* * *} \\
(0.831)\end{array}$ & $\begin{array}{c}-6.157^{* * *} \\
(1.038)\end{array}$ \\
\hline High price $\mathrm{X}$ Depletion & $\begin{array}{c}-0.806 \\
(0.738)\end{array}$ & $\begin{array}{c}-2.019^{* *} \\
(1.010)\end{array}$ & $\begin{array}{c}1.264^{*} \\
(0.653)\end{array}$ \\
\hline High price $\mathrm{X}$ Placebo & $\begin{array}{c}-1.393^{* *} \\
(0.686)\end{array}$ & $\begin{array}{c}-2.271^{* *} \\
(0.967)\end{array}$ & $\begin{array}{c}0.268 \\
(0.454)\end{array}$ \\
\hline High price $X$ Sugar & $\begin{array}{c}-1.208^{*} \\
(0.686)\end{array}$ & $\begin{array}{c}-3.020^{* * *} \\
(0.883)\end{array}$ & $\begin{array}{l}0.995^{* *} \\
(0.441)\end{array}$ \\
\hline Clusters & 149 & 74 & 75 \\
\hline Observations & 6705 & 3330 & 3375 \\
\hline
\end{tabular}


Table 4: Treatment Effects on Aggregate Utility Parameter Estimates Estimation Sample

\begin{tabular}{|c|c|c|c|}
\hline & All Subjects & Lower-Score & High-Score \\
\hline & (1) & (2) & (3) \\
\hline \multicolumn{4}{|l|}{$\alpha$ (Utility Curvature) } \\
\hline Constant (Baseline) & $\begin{array}{c}0.904 \\
(0.015)\end{array}$ & $\begin{array}{c}0.860 \\
(0.027)\end{array}$ & $\begin{array}{c}0.961 \\
(0.007)\end{array}$ \\
\hline Depletion Effect & $\begin{array}{c}0.028 \\
(0.018)\end{array}$ & $\begin{array}{l}0.058^{*} \\
(0.031)\end{array}$ & $\begin{array}{l}-0.016 \\
(0.013)\end{array}$ \\
\hline Placebo Effect & $\begin{array}{l}0.042^{* *} \\
(0.016)\end{array}$ & $\begin{array}{c}0.087^{* * *} \\
(0.028)\end{array}$ & $\begin{array}{l}-0.014 \\
(0.013)\end{array}$ \\
\hline Sugar Effect & $\begin{array}{l}0.036^{* *} \\
(0.016)\end{array}$ & $\begin{array}{c}0.105^{* * *} \\
(0.028)\end{array}$ & $\begin{array}{c}-0.030^{* * *} \\
(0.011)\end{array}$ \\
\hline \multicolumn{4}{|l|}{$\beta$ (Present Bias) } \\
\hline Constant (Baseline) & $\begin{array}{c}0.979 \\
(0.016)\end{array}$ & $\begin{array}{c}0.949 \\
(0.026)\end{array}$ & $\begin{array}{c}1.002 \\
(0.013)\end{array}$ \\
\hline Depletion Effect & $\begin{array}{c}0.006 \\
(0.018)\end{array}$ & $\begin{array}{c}0.045 \\
(0.027)\end{array}$ & $\begin{array}{l}-0.023 \\
(0.018)\end{array}$ \\
\hline Placebo Effect & $\begin{array}{c}0.004 \\
(0.018)\end{array}$ & $\begin{array}{c}0.031 \\
(0.029)\end{array}$ & $\begin{array}{l}-0.014 \\
(0.018)\end{array}$ \\
\hline Sugar Effect & $\begin{array}{c}0.004 \\
(0.019)\end{array}$ & $\begin{array}{c}0.025 \\
(0.029)\end{array}$ & $\begin{array}{l}-0.016 \\
(0.018)\end{array}$ \\
\hline \multicolumn{4}{|c|}{$r$ (Annual Discount Rate) } \\
\hline Constant (Baseline) & $\begin{array}{c}0.268 \\
(0.106)\end{array}$ & $\begin{array}{c}0.357 \\
(0.225)\end{array}$ & $\begin{array}{c}0.210 \\
(0.068)\end{array}$ \\
\hline Depletion Effect & $\begin{array}{l}-0.140 \\
(0.124)\end{array}$ & $\begin{array}{l}-0.267 \\
(0.256)\end{array}$ & $\begin{array}{l}-0.057 \\
(0.097)\end{array}$ \\
\hline Placebo Effect & $\begin{array}{l}-0.046 \\
(0.121)\end{array}$ & $\begin{array}{l}-0.076 \\
(0.236)\end{array}$ & $\begin{array}{l}-0.076 \\
(0.114)\end{array}$ \\
\hline Sugar Effect & $\begin{array}{l}-0.016 \\
(0.122)\end{array}$ & $\begin{array}{l}-0.219 \\
(0.237)\end{array}$ & $\begin{array}{c}0.109 \\
(0.107)\end{array}$ \\
\hline Clusters & 149 & 74 & 75 \\
\hline Observations & 6705 & 3330 & 3375 \\
\hline
\end{tabular}

Standard Errors in parentheses, clustered by individual. 45 observations (budgets) per cluster. 
Table 5: Treatment Effects on Median Individual Utility Parameter Estimates Estimation Sample

\begin{tabular}{|c|c|c|c|}
\hline & All Subjects & Lower-Score & High-Score \\
\hline & (1) & (2) & (3) \\
\hline \multicolumn{4}{|c|}{$\alpha$ (Utility Curvature) } \\
\hline Constant (Baseline) & $\begin{array}{c}0.958 \\
(0.009)\end{array}$ & $\begin{array}{c}0.940 \\
(0.011)\end{array}$ & $\begin{array}{c}0.974 \\
(0.008)\end{array}$ \\
\hline Depletion Effect & $\begin{array}{c}0.016 \\
(0.010)\end{array}$ & $\begin{array}{c}0.023^{*} \\
(0.013)\end{array}$ & $\begin{array}{c}0.008 \\
(0.014)\end{array}$ \\
\hline Placebo Effect & $\begin{array}{c}0.012 \\
(0.012)\end{array}$ & $\begin{array}{c}0.027^{*} \\
(0.015)\end{array}$ & $\begin{array}{c}0.005 \\
(0.019)\end{array}$ \\
\hline Sugar Effect & $\begin{array}{c}0.010 \\
(0.011)\end{array}$ & $\begin{array}{c}0.039^{* * *} \\
(0.013)\end{array}$ & $\begin{array}{c}-0.011 \\
(0.011)\end{array}$ \\
\hline \multicolumn{4}{|l|}{$\beta$ (Present Bias) } \\
\hline Constant (Baseline) & $\begin{array}{c}0.979 \\
(0.026)\end{array}$ & $\begin{array}{c}0.949 \\
(0.028)\end{array}$ & $\begin{array}{c}1.013 \\
(0.014)\end{array}$ \\
\hline Depletion Effect & $\begin{array}{l}-0.002 \\
(0.027)\end{array}$ & $\begin{array}{c}0.041 \\
(0.030)\end{array}$ & $\begin{array}{c}-0.035^{* *} \\
(0.016)\end{array}$ \\
\hline Placebo Effect & $\begin{array}{c}0.013 \\
(0.026)\end{array}$ & $\begin{array}{c}0.047 \\
(0.030)\end{array}$ & $\begin{array}{l}-0.023 \\
(0.019)\end{array}$ \\
\hline Sugar Effect & $\begin{array}{c}-0.001 \\
(0.029)\end{array}$ & $\begin{array}{c}0.018 \\
(0.037)\end{array}$ & $\begin{array}{c}-0.035^{*} \\
(0.019)\end{array}$ \\
\hline \multicolumn{4}{|c|}{$r$ (Annual Discount Rate) } \\
\hline Constant (Baseline) & $\begin{array}{c}0.323 \\
(0.104)\end{array}$ & $\begin{array}{c}0.490 \\
(0.250)\end{array}$ & $\begin{array}{c}0.323 \\
(0.073)\end{array}$ \\
\hline Depletion Effect & $\begin{array}{c}0.048 \\
(0.143)\end{array}$ & $\begin{array}{c}0.017 \\
(0.285)\end{array}$ & $\begin{array}{c}-0.081 \\
(0.140)\end{array}$ \\
\hline Placebo Effect & $\begin{array}{c}0.105 \\
(0.148)\end{array}$ & $\begin{array}{c}-0.040 \\
(0.272)\end{array}$ & $\begin{array}{c}-0.034 \\
(0.192)\end{array}$ \\
\hline Sugar Effect & $\begin{array}{l}-0.000 \\
(0.130)\end{array}$ & $\begin{array}{c}-0.311 \\
(0.273)\end{array}$ & $\begin{array}{c}0.109 \\
(0.149)\end{array}$ \\
\hline Observations & 104 & 46 & 58 \\
\hline
\end{tabular}


Table 6: Treatment Effect on Early Payment Demand with Meal Time Controls Estimation Sample

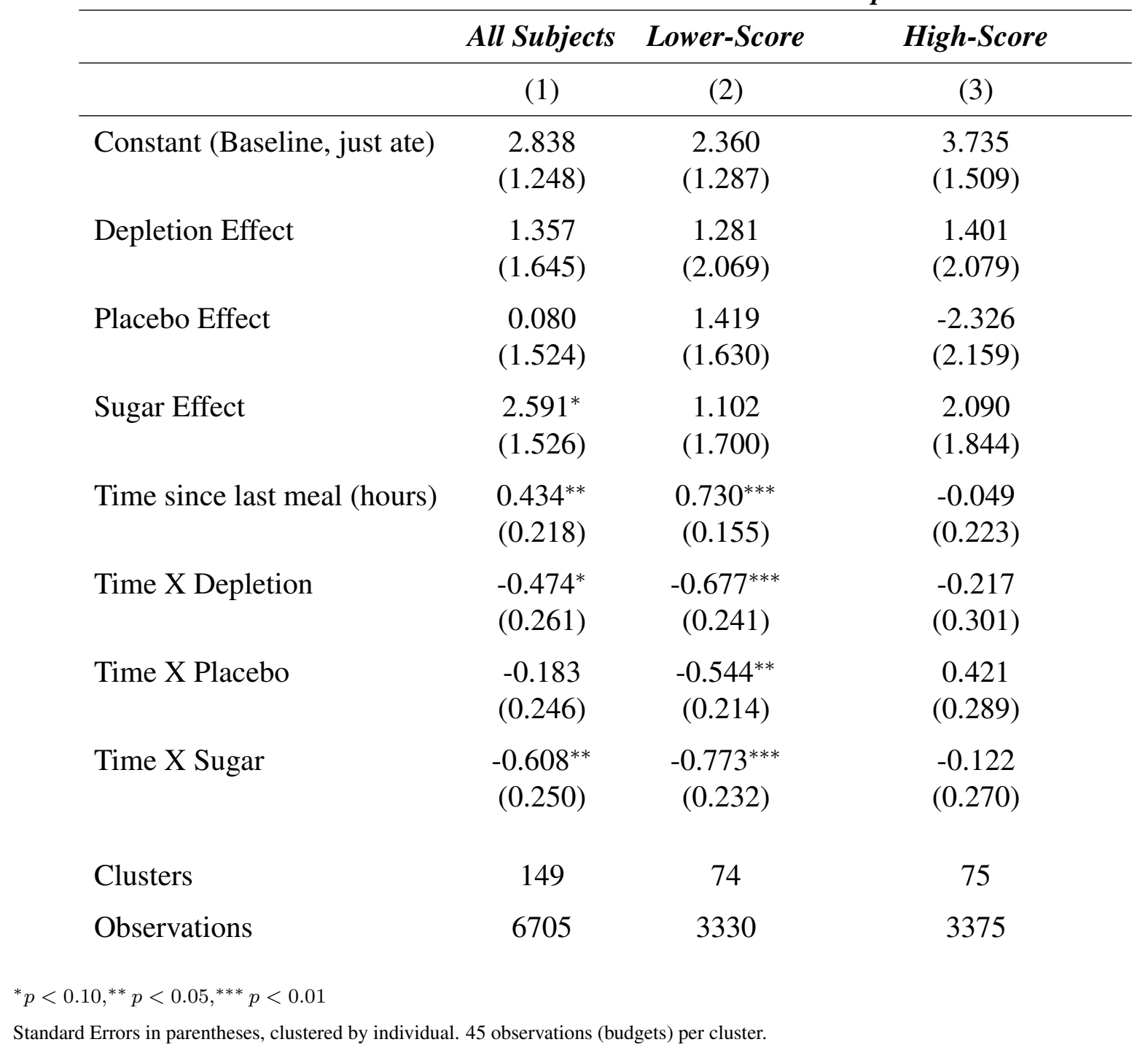


Table 7: Treatment Effect on Early Payment Demand by CRT Score Estimation Sample

\begin{tabular}{lcccc}
\hline & $\boldsymbol{C R T}=\mathbf{0}$ & $\boldsymbol{C R T}=\mathbf{1}$ & $\boldsymbol{C R T = 2}$ & $\boldsymbol{C R T = 3}$ \\
\hline & $(1)$ & $(2)$ & $(3)$ & $(4)$ \\
\hline Constant (Baseline) & 6.916 & 5.061 & 3.039 & 4.654 \\
& $(0.997)$ & $(0.965)$ & $(1.165)$ & $(2.410)$ \\
Depletion Effect & $-3.580^{* *}$ & -1.457 & 0.796 & 1.296 \\
& $(1.405)$ & $(1.635)$ & $(1.345)$ & $(3.015)$ \\
Placebo Effect & $-2.468^{*}$ & 0.251 & 0.096 & -0.726 \\
& $(1.240)$ & $(1.319)$ & $(1.653)$ & $(2.559)$ \\
Sugar Effect & $-2.409^{*}$ & -0.217 & 1.143. & -0.299 \\
& $(1.351)$ & $(1.260)$ & $(1.728)$ & $(2.599)$ \\
Clusters & & & & \\
Observations & 189 & 40 & 40 & 27 \\
& & 1800 & 1800 & 1215
\end{tabular}

${ }^{*} p<0.10,{ }^{* *} p<0.05,{ }^{* * *} p<0.01$

Standard Errors in parentheses, clustered by individual. 45 observations (budgets) per cluster. 


\section{A Appendix}

Table A1: The 45 Choice Sets in the Time Preference Elicitation Task

\section{Parameter}

\begin{tabular}{|c|c|c|c|c|c|c|}
\hline $\begin{array}{l}\text { Choice } \\
\text { number }\end{array}$ & $\begin{array}{c}\text { Early date } \\
\qquad t\end{array}$ & $\begin{array}{c}\text { Delay length } \\
k\end{array}$ & $\begin{array}{c}\text { Early value of } \\
1 \text { token } a_{t}\end{array}$ & $\begin{array}{l}\text { Price of an } \\
\text { early Euro }\end{array}$ & $\begin{array}{l}\text { Annual intrest } \\
\text { rate } \%\end{array}$ & $\begin{array}{l}\text { Maximum early } \\
\text { payoff }\end{array}$ \\
\hline 1 & 0 & 5 & 0.97 & 1.03 & 36 & 15.52 \\
\hline 2 & 0 & 5 & 0.95 & 1.05 & 65 & 15.20 \\
\hline 3 & 0 & 5 & 0.93 & 1.08 & 100 & 14.88 \\
\hline 4 & 0 & 5 & 0.91 & 1.10 & 141 & 14.56 \\
\hline 5 & 0 & 5 & 0.89 & 1.12 & 189 & 14.24 \\
\hline 6 & 5 & 10 & 0.97 & 1.03 & 17 & 15.52 \\
\hline 7 & 5 & 10 & 0.94 & 1.06 & 36 & 15.04 \\
\hline 8 & 5 & 10 & 0.91 & 1.10 & 59 & 14.56 \\
\hline 9 & 5 & 10 & 0.88 & 1.14 & 85 & 14.08 \\
\hline 10 & 5 & 10 & 0.85 & 1.18 & 116 & 13.60 \\
\hline 11 & 15 & 15 & 0.97 & 1.03 & 11 & 15.52 \\
\hline 12 & 15 & 15 & 0.93 & 1.08 & 28 & 14.88 \\
\hline 13 & 15 & 15 & 0.89 & 1.12 & 47 & 14.24 \\
\hline 14 & 15 & 15 & 0.85 & 1.18 & 70 & 13.60 \\
\hline 15 & 15 & 15 & 0.81 & 1.23 & 96 & 12.96 \\
\hline 16 & 0 & 10 & 0.98 & 1.02 & 11 & 15.68 \\
\hline 17 & 0 & 10 & 0.93 & 1.08 & 44 & 14.88 \\
\hline 18 & 0 & 10 & 0.88 & 1.14 & 85 & 14.08 \\
\hline 19 & 0 & 10 & 0.83 & 1.20 & 139 & 13.28 \\
\hline 20 & 0 & 10 & 0.78 & 1.28 & 208 & 12.48 \\
\hline 21 & 5 & 15 & 0.98 & 1.02 & 7 & 15.68 \\
\hline 22 & 5 & 15 & 0.92 & 1.09 & 32 & 14.72 \\
\hline 23 & 5 & 15 & 0.86 & 1.16 & 64 & 13.76 \\
\hline 24 & 5 & 15 & 0.80 & 1.25 & 103 & 12.80 \\
\hline 25 & 5 & 15 & 0.74 & 1.35 & 154 & 11.84 \\
\hline 26 & 15 & 5 & 0.98 & 1.02 & 23 & 15.68 \\
\hline 27 & 15 & 5 & 0.94 & 1.06 & 82 & 15.04 \\
\hline 28 & 15 & 5 & 0.90 & 1.11 & 164 & 14.40 \\
\hline 29 & 15 & 5 & 0.86 & 1.16 & 278 & 13.76 \\
\hline 30 & 15 & 5 & 0.82 & 1.22 & 432 & 13.12 \\
\hline 31 & 0 & 15 & 0.99 & 1.01 & 4 & 15.84 \\
\hline 32 & 0 & 15 & 0.91 & 1.10 & 37 & 14.56 \\
\hline 33 & 0 & 15 & 0.83 & 1.20 & 83 & 13.28 \\
\hline 34 & 0 & 15 & 0.75 & 1.33 & 144 & 12.00 \\
\hline 35 & 0 & 15 & 0.67 & 1.49 & 231 & 10.72 \\
\hline 36 & 5 & 5 & 0.99 & 1.01 & 11 & 15.84 \\
\hline 37 & 5 & 5 & 0.93 & 1.08 & 100 & 14.88 \\
\hline 38 & 5 & 5 & 0.87 & 1.15 & 246 & 13.92 \\
\hline 39 & 5 & 5 & 0.81 & 1.23 & 479 & 12.96 \\
\hline 40 & 5 & 5 & 0.75 & 1.33 & 845 & 12.00 \\
\hline 41 & 15 & 10 & 0.99 & 1.01 & 5 & 15.84 \\
\hline 42 & 15 & 10 & 0.92 & 1.09 & 51 & 14.72 \\
\hline 43 & 15 & 10 & 0.85 & 1.18 & 116 & 13.60 \\
\hline 44 & 15 & 10 & 0.78 & 1.28 & 208 & 12.48 \\
\hline 45 & 15 & 10 & 0.71 & 1.41 & 339 & 11.36 \\
\hline
\end{tabular}




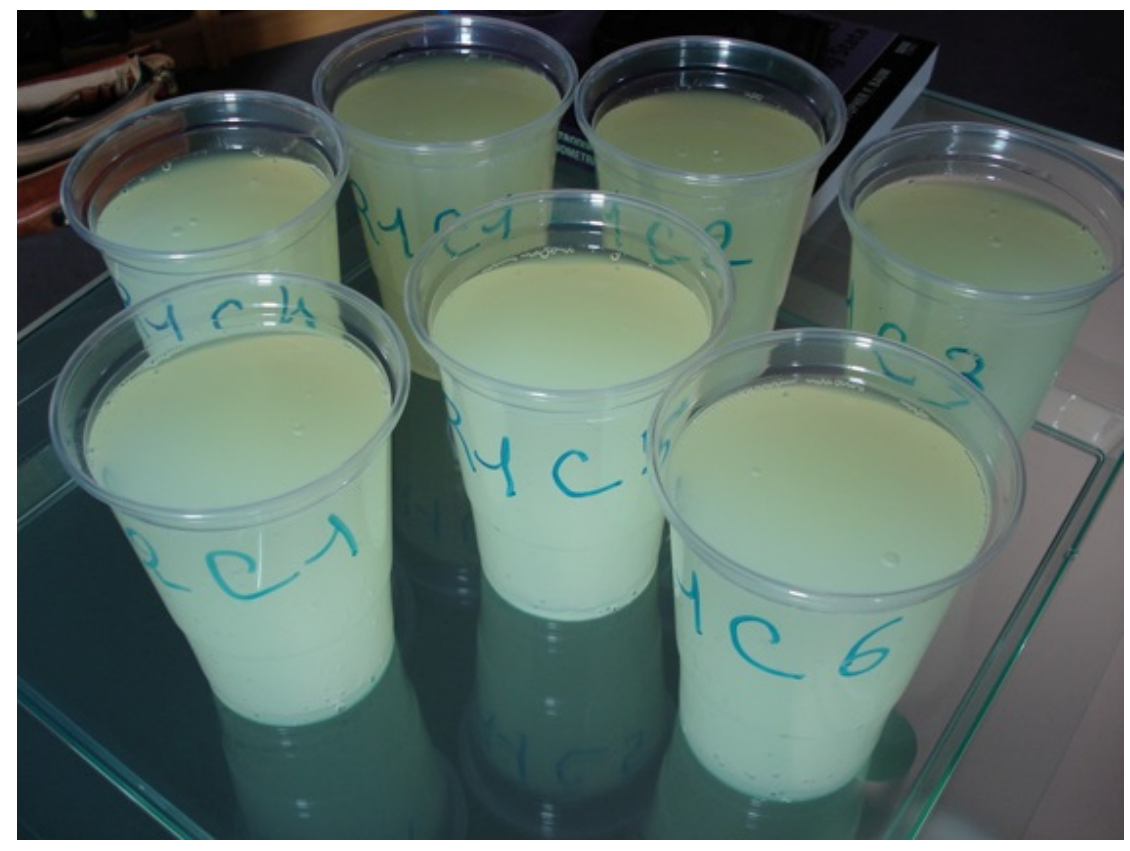

Figure A1: Glasses Containing either the Placebo or the Sugared Beverage 

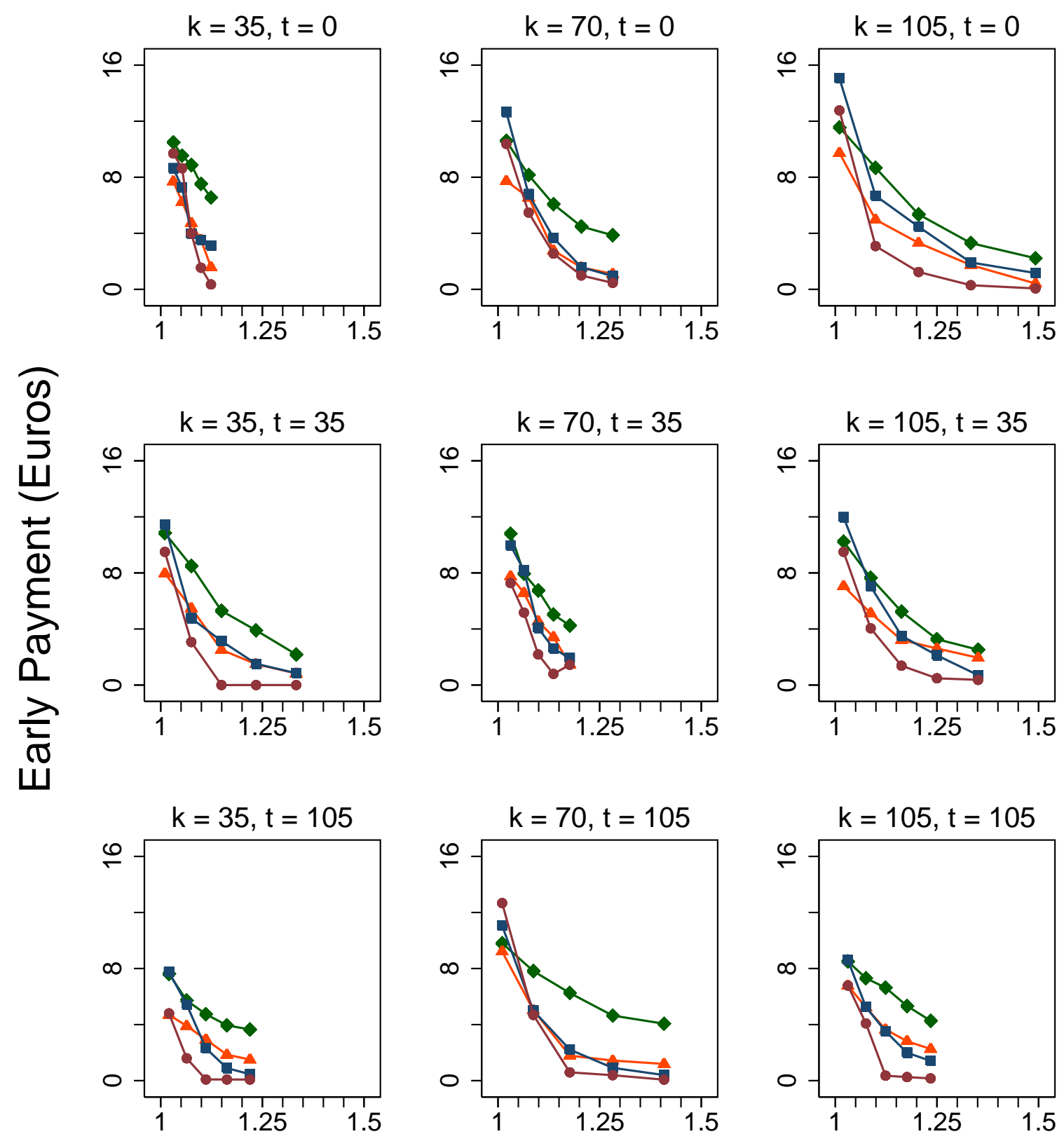

\section{Price of an Early Euro (in Late Euros)}

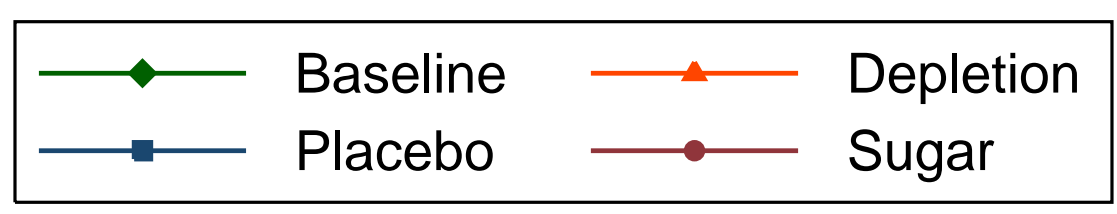

Figure A2: Demand Functions by Treatment, Lower-Score Sample 

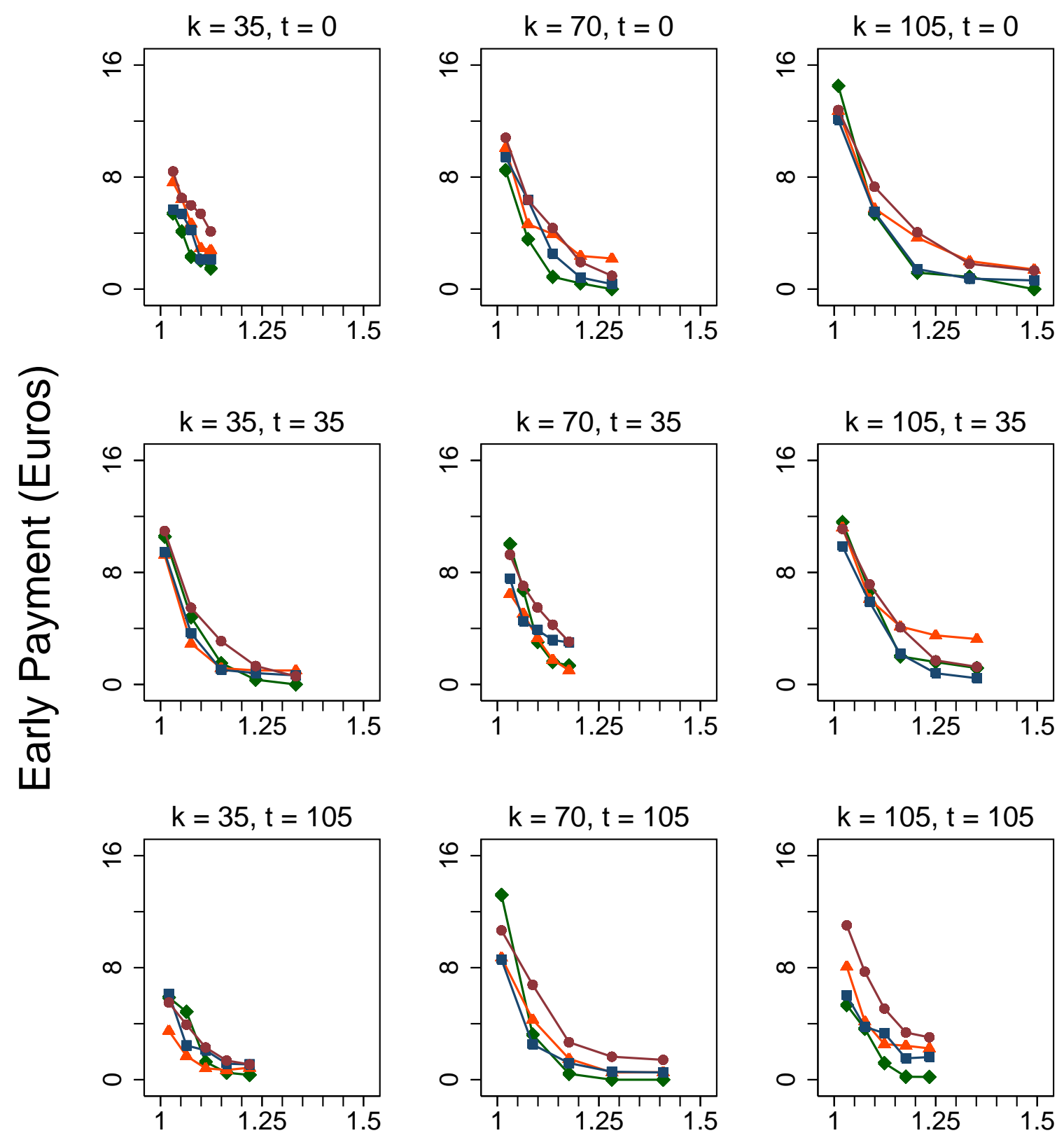

\section{Price of an Early Euro (in Late Euros)}

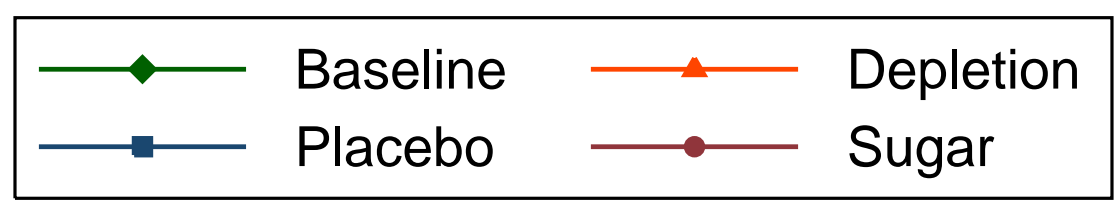

Figure A3: Demand Functions by Treatment, High-Score Sample 
Table A2: Treatment Effect on Early Payment Demand with Mood Controls

\begin{tabular}{|c|c|c|c|}
\hline & \multicolumn{3}{|c|}{ Estimation Sample } \\
\hline & All Subjects & Lower-Score & High-Score \\
\hline & (1) & (2) & (3) \\
\hline Constant (Baseline, neutral mood) & $\begin{array}{c}5.168 \\
(2.506)\end{array}$ & $\begin{array}{c}7.898 \\
(3.551)\end{array}$ & $\begin{array}{c}2.638 \\
(2.112)\end{array}$ \\
\hline Placebo Effect & $\begin{array}{c}-1.144 \\
(0.834)\end{array}$ & $\begin{array}{l}-1.922 \\
(1.163)\end{array}$ & $\begin{array}{c}-0.412 \\
(0.998)\end{array}$ \\
\hline Sugar Effect & $\begin{array}{c}-0.878 \\
(0.847)\end{array}$ & $\begin{array}{c}-3.407^{* * *} \\
(1.120)\end{array}$ & $\begin{array}{c}1.567^{*} \\
(0.900)\end{array}$ \\
\hline Mood ( -5 to 5 scale) & $\begin{array}{c}0.046 \\
(0.438)\end{array}$ & $\begin{array}{l}-0.260 \\
(0.598)\end{array}$ & $\begin{array}{c}0.160 \\
(0.424)\end{array}$ \\
\hline Mood X Placebo & $\begin{array}{c}-0.383 \\
(0.539)\end{array}$ & $\begin{array}{c}0.381 \\
(0.754)\end{array}$ & $\begin{array}{c}-1.008^{*} \\
(0.586)\end{array}$ \\
\hline Mood X Sugar & $\begin{array}{c}-0.141 \\
(0.527)\end{array}$ & $\begin{array}{c}0.648 \\
(0.679)\end{array}$ & $\begin{array}{c}-0.500 \\
(0.558)\end{array}$ \\
\hline Clusters & 109 & 55 & 54 \\
\hline Observations & 4905 & 2475 & 2430 \\
\hline
\end{tabular}

${ }^{*} p<0.10,{ }^{* *} p<0.05,{ }^{* * *} p<0.01$

Standard Errors in parentheses, clustered by individual. 45 observations (budgets) per cluster. Mood is elicited on a 1-10 scale. We renormalize to -5 to 5 such that treatment effect estimates refer to neutral mood. 
Table A3: Treatment Effect on Early Payment Demand with Drink Enjoyment Controls Estimation Sample

\begin{tabular}{|c|c|c|c|}
\hline & All Subjects & Lower-Score & High-Score \\
\hline & (1) & (2) & (3) \\
\hline Constant (Baseline, neutral enjoyment) & $\begin{array}{c}5.408 \\
(0.674)\end{array}$ & $\begin{array}{c}6.491 \\
(0.896)\end{array}$ & $\begin{array}{c}3.422 \\
(0.681)\end{array}$ \\
\hline Placebo Effect & $\begin{array}{c}-1.258 \\
(0.809)\end{array}$ & $\begin{array}{l}-1.852^{*} \\
(1.037)\end{array}$ & $\begin{array}{c}0.004 \\
(1.021)\end{array}$ \\
\hline Sugar Effect & $\begin{array}{c}-1.054 \\
(0.803)\end{array}$ & $\begin{array}{c}-3.344^{* * *} \\
(1.107)\end{array}$ & $\begin{array}{c}1.385 \\
(0.862)\end{array}$ \\
\hline Placebo X Enjoyment (-5 to 5 scale) & $\begin{array}{c}-0.231 \\
(0.160)\end{array}$ & $\begin{array}{l}-0.162 \\
(0.172)\end{array}$ & $\begin{array}{l}-0.318 \\
(0.277)\end{array}$ \\
\hline Sugar X Enjoyment (-5 to 5 scale) & $\begin{array}{c}0.296^{*} \\
(0.172)\end{array}$ & $\begin{array}{c}0.072 \\
(0.191)\end{array}$ & $\begin{array}{c}0.373^{*} \\
(0.196)\end{array}$ \\
\hline Clusters & 109 & 55 & 54 \\
\hline Observations & 4905 & 2475 & 2430 \\
\hline \multicolumn{4}{|l|}{${ }^{*} p<0.10,{ }^{* *} p<0.05,{ }^{* * *} p<0.01$} \\
\hline $\begin{array}{l}\text { tandard Errors in parentheses, clustered by individual. } 45 \text { ob } \\
-5 \text { to } 5 \text { such that treatment effect estimates refer to neutral }\end{array}$ & $\begin{array}{l}\text { vations (budgets) pe } \\
\text { ioyment. }\end{array}$ & luster. Enjoyment is & $1-10$ scale. We \\
\hline
\end{tabular}


Table A4: Treatment Effects on Probability of Corner Solution Choice Marginal Effects from Multinomial Logit Model

Estimation Sample

\begin{tabular}{lcccccc}
\hline & \multicolumn{2}{c}{ All Subjects } & \multicolumn{2}{c}{ Lower-Score } & \multicolumn{2}{c}{ High-Score } \\
\hline Corner Choice: & Sooner & Later & Sooner & Later & Sooner & Later \\
& $(1)$ & $(2)$ & $(3)$ & $(4)$ & $(5)$ & $(6)$ \\
\hline Constant (Basline) & 0.242 & 0.472 & 0.287 & 0.344 & 0.161 & 0.706 \\
& $(0.046)$ & $(0.060)$ & $(0.066)$ & $(0.072)$ & $(0.038)$ & $(0.069)$ \\
Depletion Effect & -0.063 & $0.149^{*}$ & $-0.142^{*}$ & $0.217^{* *}$ & 0.049 & -0.030 \\
& $(0.057)$ & $(0.078)$ & $(0.084)$ & $(0.108)$ & $(0.058)$ & $(0.089)$ \\
Placebo Effect & -0.055 & 0.111 & -0.077 & $0.179^{*}$ & -0.009 & -0.033 \\
& $(0.054)$ & $(0.080)$ & $(0.075)$ & $(0.096)$ & $(0.059)$ & $(0.111)$ \\
Sugar Effect & -0.061 & 0.060 & $-1.156^{* *}$ & $0.307^{* * *}$ & 0.040 & $-0.217^{* *}$ \\
& $(0.054)$ & $(0.078)$ & $(0.071)$ & $(0.105)$ & $(0.053)$ & $(0.091)$
\end{tabular}

$\begin{array}{llll}\text { Clusters } & 149 & 74 & 75\end{array}$

$\begin{array}{lll}\text { Observations } & 6705 & 3330\end{array}$

${ }^{*} p<0.10,{ }^{* *} p<0.05,{ }^{* * *} p<0.01$

Standard Errors in parentheses, clustered by individual. 45 observations (budgets) per cluster. The multinomial logit specification estimates the effect of our treatments on the probability of choosing either the sooner or later corner solution, with respect to an interior choice (all pooled). This table presents the marginal effects of changing the treatment indicators from 0 to 1 , holding the other indicators constant at 0 . 


\section{Instructions}

You are about to participate in an experimental session on decision-making.

The session consists of several parts. You will receive the instructions for each part after the previous part has been completed.

\section{Part 1}

Your computer screen will display a number of questions. We thank you for answering these questions with care.

Once all participants will have answered these questions, we will distribute glasses of a beverage that we will invite you to drink. Please do not drink the beverage before being expressly invited to do it.

Next, you will have to answer a few questions.

After you have answered these questions, you will have to wait for the next part. During this rest period, you are allowed to read books, newspapers or magazines. During this part and throughout the session, it is not allowed to talk to the other participants. 


\section{Part 2}

\section{Your decisions}

In this part, you will be asked to make a series of choices between payments you can receive at different dates. On each of nine decision screens, you will decide how to divide your payment for the experiment between two dates: an 'early' date and a 'late' date.

Altogether, you will make a total of 45 choices on the nine decision screens. These decision screens will be displayed in a random order. You will have the following options for payment dates:

Decide between payment today and payment in $\underline{5 \text { weeks }}$

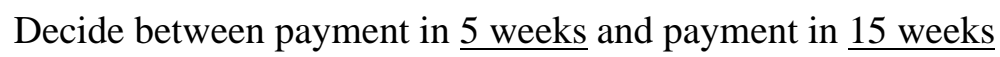

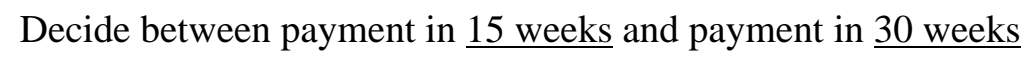

Decide between payment today and payment in 10 weeks

Decide between payment in $\underline{5 \text { weeks }}$ and payment in $\underline{20 \text { weeks }}$

Decide between payment in $\underline{15 \text { weeks }}$ and payment in $\underline{20 \text { weeks }}$

Decide between payment today and payment in $\underline{15 \text { weeks }}$

Decide between payment in $\underline{5 \text { weeks }}$ and payment in $\underline{10 \text { weeks }}$

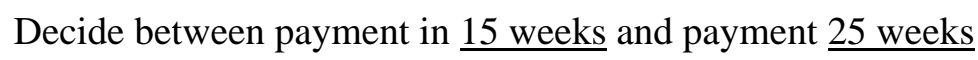

On each decision screen, we will provide you with the exact calendar dates of the above payments, so you know exactly which decision you are making. Today's date appears in green, the early payment date appears in blue and the late payment date appears in red.

You will be given 16 tokens to divide in each choice, but the value of a token changes from choice to choice. The real money payments associated with your token choices will be automatically calculated for you to see as you make your decisions.

To make your decisions, you can enter a number for the early payment (or the late payment) and move the up and down arrows. The box corresponding to the late payment (or the early payment, respectively) will be automatically updated by a number indicating the difference between 16 and the tokens assigned to the other date of payment.

Once you have completed a set of five decisions, you must press the "Validate" button to move to the next decision screen.

Below is an example of a decision screen. 


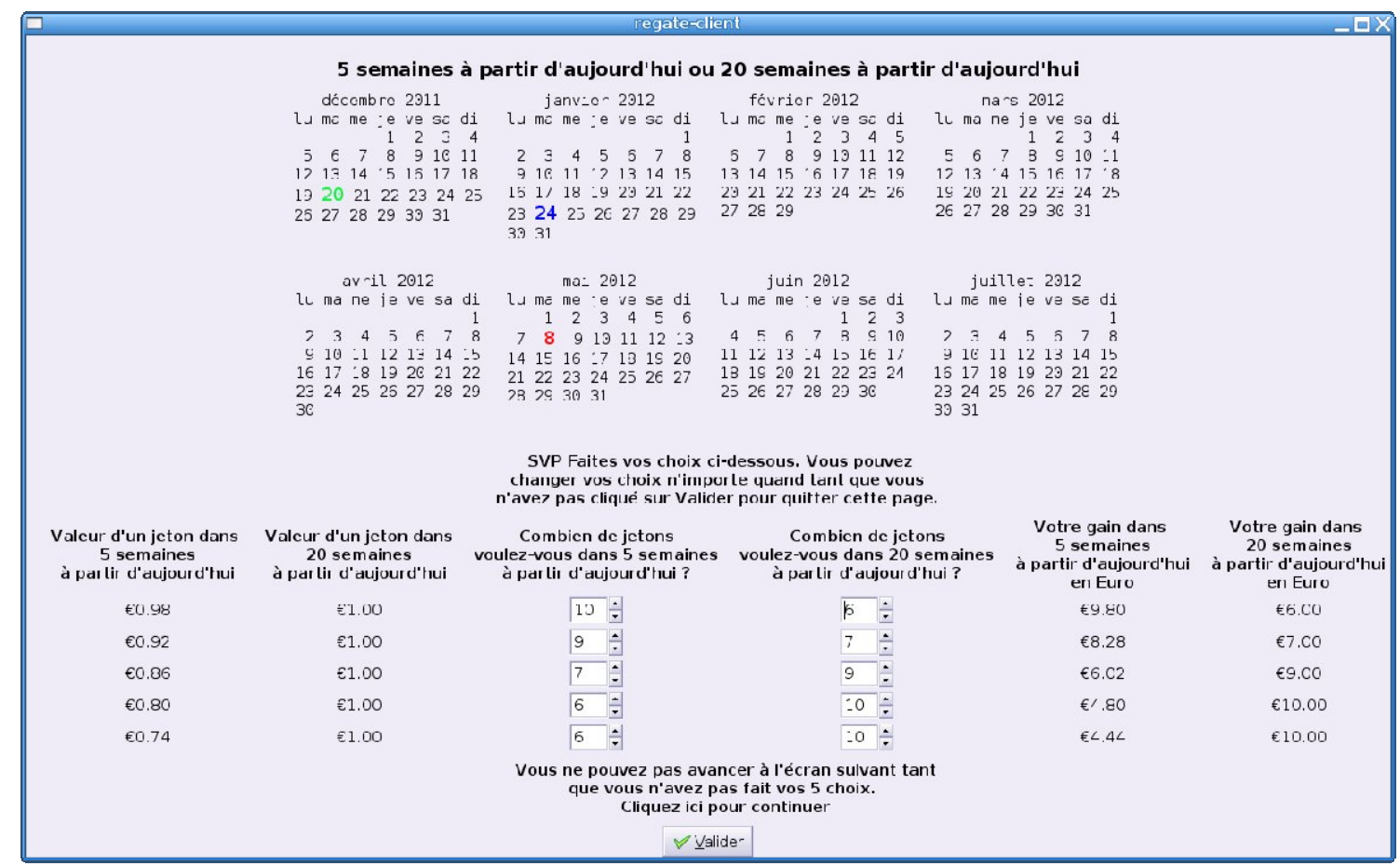

\section{Your payment}

At the end of the session, the computer program will randomly select one of the 45 decisions you made to be your earnings from participating in this experiment.

In addition, you will receive a €5 participation payment that will be split up into two payments of €2.50: one to go along with your earnings at the early and late dates associated with the randomly selected decision.

This means that you will not be paid in cash today. You will be paid by checks that will be mailed to you at the address you will indicate on the envelopes on your desk. We will mail the envelopes at the dates corresponding to the randomly selected decision.

For example, if the selected decision indicates that you have chosen $x$ tokens today and $y$ tokens in 10 weeks, we will mail the first check today and the second check in 10 weeks from today.

Remember that each decision could be the one that counts! Treat each decision as if it could be the one that determines your payment.

If you have any question on these instructions, please raise your hand and we will answer your questions in private. 


\section{Part 3}

In this part, you will be presented with a series of color words (black, blue, yellow, green, red). These words will appear in different colors, sometimes matching the word (e.g., the word blue, written in blue), and sometimes not matching the word (e.g., the word blue, written in red).

Your job is to indicate, as quickly and accurately as possible, the color in which the word is written, whether or not that matches the word itself. Click the button that matches the color of the word. Try not to pay attention to the word, but just the color.

This task will last for six minutes.

Example :

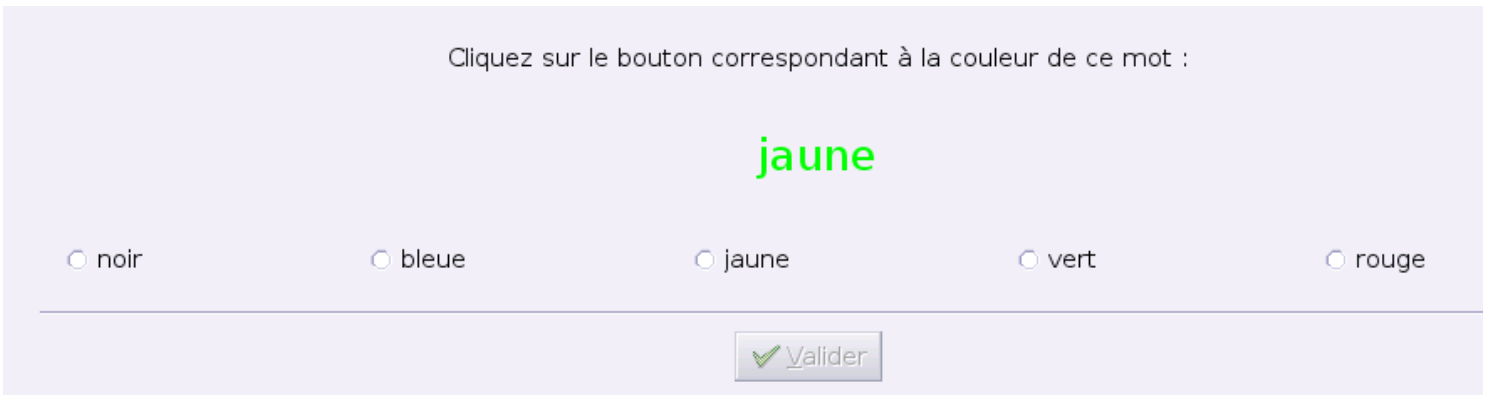

In this example, the correct answer is « green ». 